\title{
TTIP Projesi ile Beklenen Tarife Değişimlerinin Türkiye Demir Çelik İhracatı Açısından Anlamı ve Değerlendirilmesi*
}

\author{
Yasin BIYIK ${ }^{* *}$
}

\begin{abstract}
$\ddot{O} Z$
Son yıllarda $A B$ ve $A B D$ arasında tartışllagelen TTIP projesi, dünya çapında mevcut iktisadi dengeleri değiştirme potansiyeli taşıyan önemli bir projedir. TTIP sürecinin ilerleyen dönemlerinde Türkiye'nin sürece dahil olma yada olmama durumu ile ilgili farkl senaryolar altında endüstriyel ön inceleme ve analizlerin yapılması, gelecekteki gelişmelere hazırlıklı olunabilmesi açısından önemlidir. Bu çalışma ile TTIP projesi neticesinde Türkiye ekonomisinde istihdam, uluslararası ticaret hacmi, diğer endüstrilerle güçlü bağları, milli gelire katkısı açısından dikkate değer olarak düşünülen demir çelik endüstrisi ihracatındaki olası etkiler değerlendirilmeye çalışılmıştır. Türkiye'nin TTIP projesine taraf olması özellikle ABD ile karşllıklı tarifelerin giderilmesi neticesinde ihracat açısından artış sağlayabilecektir. Bu çalışmada, ticaret akışlarının modellenmesinde çekim modelinden faydalanılmış, dışsal değissken olarak TTIP projesinin ilgili ekonomilerde yaratacağ tarife değişimleri ve STA varlı̆̆ üzerinden ihracat değişimi bağıml değişken olarak analiz edilmiştir. Ekonometrik olarak, statik ve dinamik (GMM) panel veri analizlerinden faydalanılmıştır. Bulgulara göre, tarife değişken katsayısı negatif (istatistiksel anlamlı) ve STA yapay değissken katsayısı ise yalnızca GMM (dinamik model yaklaşımı altında) yöntemi altında pozitif (istatistiksel anlamsız) olarak tespit edilmiştir. Hesaplanan katsaylların istatistiksel aralıkları dikkate alınarak uygulanan simülasyon uygulama sonuçlarına göre; ABD ile uygulanagelen tarife seviyelerinin giderilmesi, Türkiye için demir çelik ihacatında önemli seviyede (\%18-24) artış yaratabilecektir. Ayrıca, TTIP'in küresel ölçekte yaratabileceği tarife azaltım dalgasının da Türkiye demir çelik ihracatı açısından anlamı dikkate değerdir.
\end{abstract}

Anahtar Kelimeler: TTIP (Transatlantik Ticaret ve Yatırım Ortakliğl/Transatlantic Trade and Investment Partnership), Türkiye Demir-Çelik İhracatı, Çekim Modeli, Monte-Carlo Simülasyonu

JEL Sinıflandırmast: F15, F10, C23, C15

\section{Meaning and Evaluation of Tariff Changes Expected with TTIP Project in terms of Iron and Steel Exports of Turkey}

\begin{abstract}
TTIP project which has been discussing among the EU and USA in recent years is a significant one that carrying potential to change current economical balances throughout the world. Industrial preliminary examination and analyses under the TTIP scenarios whether Turkey will be involved or not in to the processes of the project are important to be able to get ready for developments in future. Through this study, potential effects of TTIP project on exports of iron and steel industry that is considered as remarkable regarding its contribution into economies of Turkey in terms of employment, international trade volume, strong connection with other industries, and

Çalışma, yazarın İTÜ İşletme Mühendisliği Öğretim Üyesi Sayın Prof. Dr. N. Lerzan ÖZKALE danışmanlığındaki doktora çalışmalarının bir parçasını oluşturmaktadır.

** İstanbul Teknik Üniversitesi, İşletme Mühendisliği Bölümü, ybiyik@itu.edu.tr
\end{abstract}


additive to the national income are tried to be evaluated. As being part of TTIP particularly through removing tariffs bilaterally with USA, Turkey might be get increase in its exports. In this study, the gravity model is utilized for modeling the trade flows, changing of exports as a dependent variable is analyzed under the conditions of tariff changes and existence of FTA as exogenous variables those are affected by the TTIP project. Static and dynamic (GMM) panel data analyses are utilized econometrically. According to results, coefficient of tariff is estimated as negative (statistically significant) and coefficient of FTA variable is estimated as positive (statistically insignificant) only through GMM method (under dynamic model approach). Based on simulation study results applied through statistical ranges of calculated coefficients; removing tariffs have being applied with USA means significant raise (\%18-24) of iron and steel exports of Turkey. Additionally, tariff reduction wave on a global scale that could be initiated by TTIP is considerable for iron and steel export of Turkey.

Key Words: TTIP (Transatlantik Ticaret ve Yatırım Ortakllğı/Transatlantic Trade and Investment Partnership), Türkiye Demir-Çelik İhracatı, Çekim Modeli, Monte-Carlo Simülasyonu

JEL Classification: F15, F10, C23, C15

\section{GíRIŞ}

Son y1llarda Avrupa Birliği (AB) ve Amerika Birleşik Devletleri (ABD) arasında tartışılagelen Transatlantik Ticaret ve Yatırım Ortaklığı (TTIP) projesi, kendi içerisindeki ve küresel çaptaki etkilerinin yoğun olarak değerlendirilmeye çalışıldığ önemli bir gündem konusudur. Transatlantik ekonomi, toplamda yıllık \$5.5 trilyon ticari satı̧̧ gerçekleştirmekte ve sadece bu ticari faaliyetler ile ("onshored" işler) ilgili 15 milyon kişiye istihdam sağlamaktadır. Satınalma gücü paritesine göre küresel GSMH'nin \%35'ini kapsamakta, dünya ihracatının \%25'i ve dünya ithalatının \%30'unu gerçekleştirmektedir. Küresel yabancı doğrudan yatırımların \%70'i bu bölgeden dışarıya doğru ve küresel yatırım girişlerinin \%57'side bu bölgelere doğru akmaktadır (Hamilton \& Quinlan, 2015, s. 1).

Projenin makroekonomik etkilerini değerlendirmeye yönelik ön çalışmalar genel anlamda $\mathrm{AB}$ ve $\mathrm{ABD}$ ekonomileri için pozitif yönde beklenti içerisindedir. $\mathrm{Bu}$ beklentinin küresel seviyede de olumlu olacağı düşünülmektedir (Ponce \& Quinlan, 2013, s. 277-278). Farklı araştırma kurumları tarafından gerçekleştirilen etki ön değerlendirme analizlerinde daha çok genel denge analizi kullanılmıştır. Çalışmalarda iktisadi entegrasyonun etkileri, serbest ticaret anlaşması boyutu ile yani aradaki mevcut ticaret engellerinin (tarife ve tarife dış1 engeller) kaldırılması ile birlikte olası ticaret değişimleri dikkate alınarak ölçülmüştür. Gelişmiş ülkeler arasındaki ekonomik entegrasyon projelerinin bölge ülkeleri doğrudan yabanc1 yatırımcı girişlerinde de etki yaratabileceği düşünülebilir. Çeştepe ve Mıstaçoğlu (2010) çalışmasında ASEAN ve MERCOSUR örneklerini inceleyerek gerçekleştirdiği ampirik çalışmada bu doğrultuda bulgulara ulaşılmıştır. Türkiye'nin AB ile arasındaki GB dikkate alındığında TTIP projesinin bu kapsamdaki etkileri beklenmekte ancak bu kapsam çalışma içerisine dahil edilmemiştir. Ancak projenin serbest ticaret anlaşmasını (STA) aşan boyuttaki amaçları ve etkileri de ayrıca yoğun olarak tartışılmaktadır (Hilary, 2013). Günümüzün en önemli iktisatçılarından, Nobel ödüllü Paul Krugman (Ocak 2015) ve Joseph Stiglitz (Mayıs 2015), konu ile ilgili endişelerini ve TTIP ile ilgili olumsuz düşüncelerini dile getirmişlerdir. Bu çalışmanın gerçekleştirildiği süre içerisinde projenin uygulamaya geçmesi yönünde beklentiler ağırlık kazanmakta 
iken, özellikle ABD'deki başkanlık seçimleri sonrasında Donald Trump'ın bu alandaki politik duruşunun projenin hayata geçmesi yönündeki ihtimalleri zayıflattığı ifade edilebilir. Ancak, yine de çalışma kapsamında ticaret politika değişkenleri ile açıklanmaya çalışılan demir çelik endüstrisi ihracat modelinin ve ampirik çalışma bulgularının farklı açılardan gerek akademik gerekse de endüstriyel çalışmalara destek olacağı düşünülmektedir.

TTIP projesine yönelik eleştiriler ve tartışmalardan uzak olarak bu çalışmada sadece STA boyutu ile birlikte olası tarife değişimlerinin ihracata olan etkileri üzerine odaklanılmaktadır. Konu ile ilgili literatürde yer alan çalışmalar, modelleme ve senaryo analizleri konusunda farklılıklar içermektedir. TTIP projesinin iktisadi amacını belirleyen çıkış noktası olarak ifade edilen OECD (2005) çalışmasında, OECD ülkeleri içerisinde rekabet sınırlayıcı düzenlemelerin, tarifelerin ve yabancı doğrudan yatırım engellerinin azaltılması şeklindeki reform uygulamaları ile ekonomilerde kişi başına düşen milli gelirin \%4-5 seviyesinde arttırılabileceği öngörülmektedir (OECD, 2005, s. 6). Ayrıca, TTIP projesinin diğer dünya ekonomilerine olan etkileri de farklı kurumlar tarafindan gerçekleştirilen araştırmalar ile incelenmiştir. Son olarak Institute of Developing Economies tarafından gerçekleştirilen çalışmada, TTIP'in BRICS ülkelerinin reel milli gelirlerinde sirası ile $\% 0.1,-0.1,-0.09,-0.12$ ve -0.08 oranında değişim meydana getireceği ifade edilmektedir (Cai, Zhang, \& Meng, 2015, s. 15). Neticede TTIP'in üçüncü ülkelere olan etkisi; ilgili ekonominin küresel değer zincirine katılma derecesi, TTIP ülkeleri ile mevcut durumda var olan tercihli serbest ticaret anlaşmalarının doğası, ülkenin iktisadi yapısı ve bunun TTIP ekonomileri ile diğer ülke ekonomileri için anlamı ve TTIP dışında kalan ülkelerin TTIP'in getireceği yasal düzenlemelere uyum sağlama yeteneği gibi çeşitli faktörlere bağlı olacaktır (Akman,Evenett, Low, 2015, s. 2).

Türkiye için de bu alandaki gelişmeler oldukça önemlidir. Konu ile ilgili literatür ve çeşitli tartışma platformlarında Türkiye'nin projeye dahil olma yada olmama durumları tartışılmaktadır. Ancak net bir sonuca bağlanmış değildir. AB ile arasındaki Gümrük Birliği (GB) ve yoğun iktisadi ilişkiler sebebi ile projeden kısa vadede etkilenmesi muhtemeldir. Dolayısıyla Türkiye'nin durumunun özellikle dikkate alınması gerekmektedir (Kirişçi, 2015). TTIP'in dolaylı olarak regülatif uyum şeklindeki yayılma etkisinin güçlendirilmesinde komşu ülke olarak nitelendirilen Türkiye'nin mevcut ticaret yapısı ile birlikte yoğun bir inisiyatif alabileceği düşünülmektedir (Lejour, Mustilli, Pelkmans, \& Timini, 2014). ECORYS (2014)'in TTIP etkisini ölçmeye yönelik çalışma metodolojisinin ve proje ilerleme süreçlerinin açıklandığı öneri niteliğindeki taslak raporda, ayrıca Türkiye'nin durumunu analiz etmeye yönelik iş paketleri de tanımlanmıştır. Dünya Bankası (2014) çalışmasına göre Türkiye'nin sürece dahil olmas1 durumunda yaklaşık 130 milyon dolar refah artışı öngörülmektedir. Sadece ABD ile olası FTA durumunda bu refah artışı 260 milyon dolar, süreç dışında kalmasında ise sınırlarını açıp açmamaya bağlı olarak 130 ile 160 milyon dolar refah kaybı hesaplanmaktadır (The World Bank, 2014). Türkiye'nin sürece dahil olma durumunun $\mathrm{AB}$ ve $\mathrm{ABD}$ için ilave refah artışı kazanımları yaratacağı 
düşünülmektedir ${ }^{1}$ (Güneş, Mavuş, \& Oduncu, 2013). Sektör esaslı analiz kapsamında değerlendirilebilecek bu çalışma ile özünde ABD ile kurulacak STA şeklindeki TTIP senaryosu altında, Türkiye demir-çelik ihracatına olası etkilerin ölçülmesi amaçlanmaktadır. Çalışmada model olarak dış ticaretin ticarete konu olan ekonomilerin ölçeğini ve ticaret maliyetlerini temsil eden değişkenler ile açıklandığı bir ekonometrik yaklaşım olan Çekim Modeli (Gravity Model) kullanılmıştır. Ticaret politikası etkilerinin değerlendirilmesi amacıyla da kullanılan model, literatürde yaygın ve kabul görmüş bir yöntem olarak ifade edilebilir. Çekim modeli ile modellenen demir-çelik ihracatının tarife ve STA'lara olan duyarlılıkları analizler ile tespit edilmiştir. Monte-Carlo simülasyon yaklaşımı altında hesaplanan duyarlılık ile ilgili parametrelerin belirli bir istatistiksel aralık içerisinde üretilen rassal değerleri, yine belirli bir aralık dahilinde üretilen rassal tarife değişimleri ile birlikte değerlendirilerek sonuçlar yorumlanmıştır.

Türkiye'nin iktisadi büyüme anlamında ihracat bileşeninin payı oldukça önemlidir. İhracata dayalı büyüme hipotezinin geçerliliği, Özcan ve Özçelebi (2013)' nin çalışmasında doğrulanmaktadır. Bu bağlamda, imalat ve inşaat endüstrisi için temel hammadde sanayi grubu olan demir-çelik, Türkiye ekonomisinde önemli bir sanayi dalıdır. Türkiye milli gelirinde demir-çelik endüstrisinin katkısı yaklaşık \%1,2 seviyesindedir. Sektörün büyümesi, GSMH büyümesi ile yüksek seviyede ilişki içerisindedir (Deloitte, 2013). Ulusal çelik endüstrisi üretim kapasitesi 2000'li yıllarda 20 milyon ton iken 2015 yılında 52 milyon ton seviyesine çıkmıştır. Aynı dönemler için gerçekleşen reel üretim ise 14 milyon ve 31,5 milyon ton olarak seyretmiştir. Dünya ham çelik üretimi 2000 yılında 849 milyon ton iken 2015 y1lında \%91 oranında artarak 1.623 milyon ton olarak gerçekleşmiştir. Dünya ham çelik üretiminde ilk sırayı alan Çin ile birlikte, Japonya, ABD ve Hindistan öne çıkmaktadır. Türkiye 2015 y1lı dünya çelik üretimi sıralamasında 9. sırada yerini almıştır. Değersel olarak Türkiye toplam ihracatının yaklaşık \%7-8'i demir-çelik endüstrisi tarafindan gerçekleştirilmektedir (2015 Türkiye toplam ihracatı: 143.729.741.000 \$). Miktar bazında endüstrinin ihraç ettiği ürün dağılımına bakıldığına yaklaşık \%65 uzun ürün, $\% 15$ yassı ürün, $\% 12$ boru, $\% 2$ kütük ve diğerlerinden oluşmaktadır. Değer bazındaki dağılım ise yaklaşık \%49 uzun ürün, \%13 yassı ürün, $\% 14$ boru ve $\% 2$ kütük şeklindedir. Değer bazında ihracatın ülke gruplarına dağılımına bakıldığında ise \%45 MENA (Orta Doğu ve Kuzey Afrika), \%22 AB28, \%1 Uzak Doğu, \%13 ABD (Kanada dahil) ve \%5 BDT ülkeleri şeklindedir (Yazar Hesaplamaları; Kaynak: Türkiye Çelik Üreticileri Derneği, TÜiK ve TİM İstatistikleri).

\section{TTIP ETKİSİNE YÖNELİK ÇALIŞMALAR VE BULGULARI}

Literatürde, TTIP projesinin etkilerini hem $\mathrm{AB}$ ve $\mathrm{ABD}$ ekonomileri, hem de diğer dünya ülke ekonomileri kapsamında incelemeye yönelik genel denge

\footnotetext{
${ }^{1} \mathrm{Bu}$ alanda yapılan çalışmalar Hesaplanabilir Genel Denge Analizi (Computable General Equilibrium-CGE) metodolojisi ile gerçekleştirilmiş olup, söz konusu matematiksel modelde kullanılan verilerin Türkiye için güncel olmaması ve referans yıllarındaki farklılıklar nedeniyle eleştirilere açık bir niteliktedir.
} 
analizleri mevcuttur. Değerlendirmelerde genellikle GTAP $^{2}$ metodolojisinden faydalanılmakta ve ticari engellerin kaldırılması sonucunda oluşacak kısa vadeli ticaret hacmi artışı şeklindeki etki ile birlikte, uzun vadede gelişmesi beklenen rekabet koşulları ve verimlilik artışı beklentilerine de vurgu yapılmaktadır. AB ve ABD arasındaki ekonomik birlikteliğin etkilerini değerlendiren Vandenbussche ve diğerlerinin (2002) çalışmasında, tarife dışı engeller ve dinamik etkiler dikkate alınmaksızın, alt sınır (lower bound) tarife seviyesi ile gerçekleştirilen analizlerde milli gelirdeki artış $\mathrm{AB}$ için \% 0.7-0.9, ABD için \% 0.2 olarak hesaplanmıştır. Projenin en çok kayrılan ülke (MFN) tarife oranlarına etkisi ile birlikte Kanada için \%0.001, Meksika için \%0.02, ve Latin Amerika için $\% 0.3$ milli gelir artışı hesaplanmıştır. Avrupa Komisyonu tarafından ECORYS'e hazırlatılan (2009) raporda, tarife dışı engeller (TDE) ve düzenleme farklılıkları dikkate alınarak transatlantik iktisadi entegrasyonun etkileri sektörel seviyede analiz edilmiştir. Sektörel anket ve OECD indekslerinden faydalanılarak tespit edilmiş TDE'lerin ve düzenleme engellerinin sektörel ticaret seviyeleri ile ilişkisel katsayıları ekonometrik yöntemler ile saptanmıştır. Ticaret maliyetini belirleyen engellerin giderilmesi yönündeki iyimser senaryo altında $\mathrm{AB}$ milli gelirinde $0.27-0.72 \%$ (kısa ve verimlilik etkisi dikkate alınmış uzun dönem), ABD de ise 0.13-0.28\% değişim hesaplanmıştır (iyimser senaryo TDE'lerin \%50 azaltıldığı senaryo durumudur). Sektörel uzman görüşleri dikkate alınarak belirlenen sınırlı durum senaryosunda ise TDE'lerin \%25 azaltım koşulu ile AB'de 0.11-0.32, ABD'de ise 0.07-0.14 milli gelir değişimi hesaplanmıştır (Berden, Francois, Thelle, Wymenga, \& Tamminen, 2009). ECIPE'nin 2010 raporu da benzer yöntem ile $\mathrm{AB}$ için \%0.01 statik ve \%0.32-0.48 dinamik milli gelir değişimi, ABD için \%0.15 statik ve \%0.99-1.33 dinamik milli gelir değişimi öngörmektedir (Erixon \& Bauer, 2010). Fontagne ve diğerleri (2013), uzun vadede projenin milli gelir açısından AB için yıllık 98 milyar dolar, ABD için ise 64 milyar dolar artış yaratabileceğini öngörmektedir.

Ifo institute (2013) çalışması TTIP' in kendi içerisindeki etkileri ile birlikte diğer dünya ekonomileri üzerindeki etkiyi de dikkate almıştır. Transatlantik bölgede ilgili ülkelerin kendi içlerinde uyguladıkları tarifeleri kaldırmalarına bağl1 olarak, Çin, Türkiye, Güney Kore, Avusturalya, Kanada, Meksika, Arjantin, Rusya ve Hindistan' da milli gelir azalması hesaplanmıştır (Felbermayr, Larch, Flach, Yalcin, \& Benz, 2013, s. 7). Milli gelir azalması en çok Çin'de en az ise Hindistan'da olacağı öngörülmektedir. AB ile ABD arasındaki tarife engellerinin kaldırılmasında yürürlükte olan STA' ların ticari engelleri yok etme dereceleri ex post çalışmalar ile belirlenerek senaryo analizlerinde dikkate alınmaya çalışılmışıtır (Felbermayr, Heid, \& Lehwald, Transatlantic Free Trade: Winners, Losers and Necessary Accompanying Measures, 2013). Francois ve diğerleri (2013) çalışmalarında TTIP'in milli gelirler üzerindeki etkisinin ABD, $A B$ ve

\footnotetext{
${ }^{2}$ GTAP, genel denge analizi metodolojisine dayalı olarak ticaret politikası etkilerinin kantitatif araştırılmasında ortak veri tabanı ve metodoloji kullanımını öngören araştırmacılar ve politika yapıcılar arasındaki bir iletişim platformu olarak düşünülebilir. Program, Purdue Üniversitesi Tarımsal Ekonomi Departmanına bağlı Küresel Ticaret Analiz Merkezi (Center for Global Trade Analysis) tarafindan koordine edilmektedir.
} 
dünya ekonomisi geneli için olumlu yönde olacağını vurgulamaktadır. Ayrıca, TTIP'in CO2 salınımına ve doğal kaynakların sürdürülebilir olarak kullanımına ihmal edilebilecek seviyede etkisinin olacağı belirtilmiştir. Çalışmada ilave olarak yabancı doğrudan yatırımlar üzerindeki engeller dikkate alınarak ekonometrik modelleme ile söz konusu etki irdelenmeye çalış1lmıştır. Egger ve diğerlerinin (2014)'de çalışmalarında sektörel bazlı olarak tarife ve TDE'ler kapsamlı ve sistematik bir şekilde irdelenmiştir. Akabinde çekim modeli yardımıyla ticaret maliyetlerini etkileyen faktörler ve katsayıları tespit edilmiştir. Uyguladıkları genel denge analizlerine göre statik etki altında AB için \%1.14, ABD için \%0.59 olarak milli gelir artışı öngörülmektedir. Ölçülen diğer ülkelere olan milli gelir etkileri ise düşük gelirli ülke grupları dışında küresel seviyede negatif yönlüdür. Projenin uygulamaya geçmesi ile birlikte tarifelerin tamamen ortadan kaldırılması beklenmektedir. Ancak TDE'lerin tespiti, kontrolü ve izlenmesinin pratikteki zorlukları sebebiyle analizlerde belirli oranlarda azaltıldığı senaryolar üzerinden incelemeler gerçekleştirilmiştir. Engellerin yüksek seviyede ortadan kaldırıldığının varsayıldığı yayılma etkisi altında gerçekleştirilen simülasyon sonucunda tüm dünya ekonomilerinde pozitif yönde bir değişim hesaplanmıştır (s.27-28). Yine Ifo Enstitüsü (München) ve Uygulamalı Araştırmalar Enstitüsü (IAW, Tubingen) tarafindan Ocak 2015 tarihinde yayınlanan rapor özet bildirisinde TTIP'den kendi içerisindeki ülke ekonomileri ve küresel seviyede beklenen olumlu etkiler vurgulanmıştır. Literatürdeki analizlerde TTIP'in üçüncü ülkelere olan negatif etkisinin TTIP heterojenliği ile birlikte açıklanabileceği, tedarik zinciri etkisinin bu negatif etkiyi dengelemede önemli olabileceği tartışılmaktadır (Brakman, ve diğerleri, 2015).

TTIP'in küresel ormancilık endüstrisine olası etkilerinin, genel denge analizi ile öngörülen makroekonomik değişikleri dikkate alan Küresel Ormancılık Ürün Modeli (Global Forest Products Model) ile değerlendirildiği Buongiorno ve diğerleri (2014) çalışmasında, üretici ve tüketici refahında AB'de 7, ABD ise 14 milyar dolar artış sağlanacağı öngörülmektedir. Bazı Asya ülkelerinde ise refah düzeyinde azalma tespit edilmektedir. Dobrea ve diğerleri (2015), TTIP'in küresel sürdürülebilirlik konularına (kaynakların korunması, bilgi teknolojileri, sosyal sorumluluk, ekolojik problemler, vs.) olan etkilerinin irdelenmesine dikkat çekmektedir. TTIP'in çevresel açıdan riskleri de tartışılmaktadır (Federal Environment Agency, 2015). Projenin başarısının regülasyon ve standartlar ile ilgili zorlukları aşması ile sağlanabileceği belirtilmektedir. Özellikle AB'deki tüketicilerin hangi standardı takip edeceklerine yönelik seçimleri yapabilmeleri önemlidir (Freytag, ve diğerleri, 2014). TTIP'in geleneksel STA'dan öte boyutları sebebi ile paydaşları tarafından yoğun olarak şeffaf ve açık tartışmaların olması talep edilmektedir. Bu doğrultuda, AB içerisindeki lokal ve bölgesel yetkililerin rolü ve etkin bir iletişim stratejisinin önemi vurgulanmaktadır (Schneider, 2015), Sivil toplum kuruluşları tarafından genellikle sağlık ve çevresel standartların azaltılması, işgücü koşullarının zayıflatılması, iktisadi etkisinin istihdam ve büyüme üzerinde yeterli seviyede olmayacağı yönündeki olumsuz görüşler de mevcuttur (Pelkmans, 2015). 
Proje ile birlikte $\mathrm{AB}$ ve $\mathrm{ABD}$ 'nin dünya ticaretinde azalan etkisi yeniden ivme kazanabilecektir (Gostomski, et al., 2015). Ticaret indeksleri kullanılarak analizlerin gerçekleştirildiği Czarny ve diğerlerinin (2015) çalışmasında da yine projenin tüm bölge ekonomileri için olumlu etkisi vurgulanmaktadır. Transatlantik bölgesinin Çin' e karşı ayakta durabilmesi, AB'nin Rusya enerjisine bağımlılı̆̆ının azaltılması, batı ekonomik modelinin güçlendirilmesi ve $A B$ ' nin izole hale gelmesinin önüne geçilmesi açısından da projenin önemine değinilmektedir (Pavlova, 2015). Projenin birlik içerisindeki gelişmiş ülkelere daha fazla fayda sağlayacağı ve bununda bölgesel eşitsizliği arttıracağı yönünde görüş de mevcuttur (Villaverde, et al., 2016). Rojas-Romagosa (2016), tarife ve TDE'lerin önemli ölçüde azaltılması ile Hollanda-ABD arasındaki ticaret hacminin iki katına çıkabileceğini ancak milli gelirdeki değişimin 1lımlı olacağını öngörmektedir. Çalışmada Hollanda için milli gelir artışının yüzdesel olarak AB geneli ve ABD'den daha fazla olacağı öngörülmektedir. ECORYS (2016) tarafından TTIP'in Belçika'ya etkilerini irdelemek üzere gerçekleştirilen çalışmada ise, \%2.2'lik (kamu alımları etkisi hariç) hesaplanan milli gelir artışı ile bölgeler arasında en fazla artış beklenen bölge Belçika olarak tespit edilmiştir. Geri kalan $\mathrm{AB}$ bölgesi için milli gelir artışı $\% 0.47$ ve $\mathrm{ABD}$ için ise $\% 0.24$ olarak hesaplanmıştır. SER (Social and Economic Council of the Netherlands, 2016) raporunda, TTIP'in pozitif etkileri yanında bireysel firmalar ve belirli çalışan kesim açısından sonuçlarının olumsuz olabileceği belirtilmekte ve bu kesimler için gelir koruma garantisi altında gerekli önlemlerin alınmasının zorunluluğu dile getirilmektedir. TTIP'in Avrupa'ya iktisadi etkilerine yönelik argümanların azlığı ve de sosyal etkilerine yönelik herhangi bir değerlendirme yapılmadığına yönelik eleştirilerde bulunmaktadır (Beer, ve diğerleri, 2016). Arita ve diğerlerinin (2017) çalışmasında, $\mathrm{AB}$ ve $\mathrm{ABD}$ arasındaki tarım ürünleri ticaretindeki olası liberalizasyon derinleşmesinin etkileri endüstriyel seviyede ekonometrik modelleme ve genel denge analizleri ile birlikte irdelenmeye çalışılmıştır. Tarife engellerinin kaldırılmasının 6.3 milyar dolar, hijyen ve bitki sağlığı önlemleri (sanitary and phytosanitary measures) şeklindeki tarife dışı engellerin kaldırılması ile ise 11.6 milyar dolar ticaret yaratma potansiyeli belirtilmektedir.

TTIP ile ilgili Türkiye'nin durumuna bakıldığında, aradaki GB varlığ sebebiyle Türkiye AB ile ortak dış tarife uygulamaktadır. Türkiye'nin TTIP sürecine dahil olmaması $\mathrm{AB}$ ile $\mathrm{ABD}$ arasında gerçekleşecek tarife indirimlerinden doğrudan faydalanamayacağı anlamına gelecektir. Diğer bir ifadeyle, ABD ürünlerinin Türkiye'ye girişi kolay hale gelirken Türkiye menşeili ürünler ABD pazarında aynı ölçüde avantaj elde edemeyecektir. Ancak, Türkiye ihracat faaliyetleri açısından $\mathrm{AB}$ ile entegrasyonu yüksek seviyede olduğu için dolaylı olarak ihracatın gelişim etkisinden ve ithalat maliyetlerinin azalması neticesinde de potansiyel milli gelir artış etkisinden bahsedilmektedir (Felbermayr, Kohler, Aichele, Klee, \& Yalçın, 2015, s. 6). Yıllar itibariyle dünya genelinde artan bölgesel iktisadi entegrasyon uygulamalarının genel olarak diğer ekonomilerde de tarife seviyelerinde azaltma etkisi yarattığı tartışılmaktadır. TTIP şeklindeki büyük çaplı bir projenin dünya ekonomilerinde tarife azaltma 
yönünde bir inisiyatif yaratacağı ayrıca ifade edilmektedir (Lejour, Mustilli, Pelkmans, \& Timini, 2014). Bu durum analizlerde dolaylı etki olarak dikkate alınmaya çalışılmıştır. Türkiye'nin proje bünyesinde yer alması özellikle ABD ile ticari ortaklığın oluşturulması ve derinlik kazandırılması açısından önemlidir (Akman, 2014). TTIP'in dişında kalan ekonomiler için ayrımcı ve negatif sonuçlara neden olacağı beklenmektedir (Felbermayr, ve diğerleri, 2014). Projenin Türkiye'deki bazı endüstrilerde (tekstil, çimento, seramik ve cam, askeri teçhizat, sebze ürünleri, hayvanı ve bitkisel yağlar, vb.) rekabet dezavantajı etkileri, tarifelerin önemli ölçüde giderilmesi ile minimize edilebilecektir (Özçelik, 2016). Türkiye ile ilgili etki değerlendirmede entegrasyon pratiğinin psikolojik boyutunun da dikkate alınması gerekmektedir. Türkiye'nin sürecin dışında kalması ile Türkiye'de mevcut ve ABD'ye ihracat yapan firmaların gümrük vergisi avantajından faydalanmak üzere yatırımlarını AB'ye kaydırması beklenebilir (Köten, 2015). Tasarım ve markalaşma için yeterli finansal kaynak bulamayan Türkiye'deki KOBİ'lerin oldukça düşük sayıda olanları yüksek teknolojide üretim yapmaktadır. Bu nedenle TTIP sonrası dönemde AB pazarında artan bir rekabet olgusuna dikkat çekilmektedir (TÜRKONFED, 2016)

TTIP etki değerlendirme çalışmaları model, varsayım ve kapsam olarak yeterliliği tartışmaya açık bir noktadadır. Projenin etkilerinin ön değerlendirilmesi, ilgili ekonomilerin büyüklüğü, ticaret akışlarının karmaşık yapısı ve tarife dışı engellerin tespit edilebilirliğindeki güçlükler gibi nedenlerle oldukça zordur. Öte yandan bu şekilde geniş çaplı bir projenin kısmı denge analizi ile değerlendirilmesi oldukça dar bir yaklaşımdır. Genel denge analizi bu bağlamda sektörler arasındaki etkileşimi belirli bir seviyeye kadar kapsadığı için daha iyi bir yaklaşım olabilecektir. Bu tür bir projenin etkisinin ön değerlendirilmesinde kullanılacak en iyi yöntem konusunda genel denge analizi tam bir cevap oluşturmamasına rağmen, eldeki en iyi yöntem olarak ifade edilmektedir (Pelkmans, Lejour, Schrefler, Mustilli, \& Timini, 2014, s. 50-55). Genel denge analizlerinin TTIP etkisini değerlendirmedeki eksikliklerini dikkate alarak ticaret politikası etki değerlendirmede alternatif bir yöntem olarak belirtilen Birleşmiş Milletler Küresel Politika Modeli (United Nations Global Policy Model)' nin küresel ticaret, istihdam dinamikleri ve makroekonomik dengeye gelme durumu ile ilgili daha duyarlı varsayımlarının olduğu ifade edilmektedir. Capaldo (2014)'nun bu model ile birlikte gerçekleştirdiği analizler ile TTIP'in milli gelirde özellikle Kuzey Avrupa ülkelerinde \%0.5, Fransa için $\% 0.48$ ve Almanya için \%0.29 azalma yaratacağı tespit edilmiştir. Analiz sonuçlarına göre TTIP sadece ABD milli gelirinde olumlu yönde bir katk1 sağlayabilecektir (Capaldo, 2014, s. 14).

Dış ticaret akışlarının ticaret politikası değişkenleri gibi farklı değişkenler ile birlikte ampirik olarak analiz edilmesinde yaygın olarak kullanılan bir diğer yöntem olarak çekim modeli (gravity model) literatürde en çok serbest ticaret anlaşmaları ve gümrük birliği etki araştırmaları alanında kullanılmaktadır. Ayrıca son dönemlerde GATT/WTO üyeliğinin ticarete olan etkisinin araştırılması, ticaretin büyüme ve çevresel unsurlar ile olan ilişkisinin incelenmesinde de 
yaygın olarak kullanılmaktadır. Uluslararası ticaret ile ilgili çalışmalarda yaygın kullanımı modelin ticaret akışlarını açıklayabilme gücü ve ticareti etkileyebileceği düşünülen farklı değişkenlerin test edilmesinde oldukça kolay uygulanabilir bir yöntem olmasından kaynaklanmaktadır (Piermartini \& Teh, 2005, s. 37).

\section{III. ÇEKIMM MODELİ: TEORIKK ÇERÇEVESİ VE ÇÖZÜMLENMESİ}

Ekonometrik bir yöntem olarak çekim modeli (gravity model), literatürde daha çok ex-post yani ticaret politika değişkenlerinin uygulama sonrası etkilerinin değerlendirilmesinde kullanılmaktadır. Modelin yüksek varyans ve istatistiksel olarak uygun olmayan değişken katsayıları gibi teknik olarak ölçüm risklerinin var olmasına rağmen, simülasyon amaciyla ex-ante yöntem olarak kullanılabileceği de belirtilmektedir (Piermartini \& Teh, 2005). Belirtilen analiz yöntemlerini tamamen ayrıştırmak yerine her birini kendi varsayım ve koşulları altında birlikte değerlendirmek, bütünleyici ve tamamlayıcı analizler olarak bakmak belki daha doğru bir yaklaşımdır (Greenaway \& Milner, 2002, s. 12). ABD ile Güney Kore arasındaki STA' nın uygulama öncesi sektörel etki değerlendirmesinde hem genel denge hem de çekim modeli Powers (2007, s.20) çalışmasında kullanılmış ve sektörel etki itibariyle birbirleriyle ilişkili sonuçlar elde edilmiştir (korelasyon katsayısı 0.64). Modelde açıklayıcı değişkenler, ilgili ülkelerdeki talep ve arz belirleyici (milli gelir, nüfus, vs.) ve ülkeler arasındaki ticaret maliyetini belirleyici (mesafe, tarifeler, tarife dişı engeller, STA, vs.) unsurlar üzerinden değerlendirilerek seçilmektedir. İlk olarak Jan Timbergen (1962) tarafindan uluslararası ticaret alanında kullanılan modelin genel matematiksel çarpım şeklindeki denklemsel ifadesi aşağıda verilmiştir:

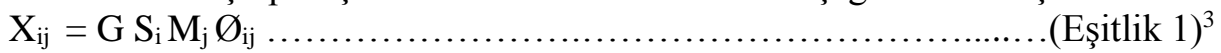

$\ln X_{\mathrm{ij}}=\ln \mathrm{G}+\ln \mathrm{S}_{\mathrm{i}}+\ln \mathrm{M}_{\mathrm{j}}+\ln \emptyset_{\mathrm{ij}} \ldots \ldots \ldots \ldots \ldots \ldots \ldots \ldots \ldots \ldots \ldots \ldots \ldots \ldots \ldots \ldots$ (Eşitlik 2)

Uygulamada hesaplamaları daha kolay hale getirebilmek amaciyla denklemin karşılıklı olarak doğal logaritması alınarak Eşitlik 2'ye ulaşılmaktadır. Daha belirgin olarak Anderson ve van Wincoop'un tanımlaması ile model denklemi Eşitlik 3 ve 4'de verilmiştir.

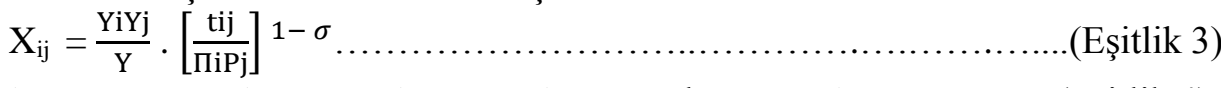

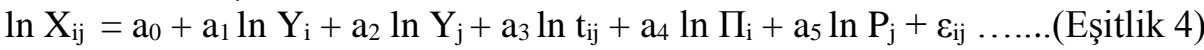

$(\mathrm{a} 3=1-\sigma)$

$Y_{i}$ ve $Y_{j} i$ ve $j$ ülkelerinin milli geliri, $t_{i j} i$ 'den j'ye ihracatın maliyeti, $\Pi_{i} i$ ülkesinin ihracat kolaylığ $1, P_{j} \mathrm{j}$ ülkesinin ithalat kolaylı̆̆ $1, \sigma$ ikame esnekliği, $a_{0}$ sabit ve $\varepsilon$ denklemin hata terimidir. Eşitlik 1 ve 2'de $\varnothing_{\mathrm{ij}}$ ve Eşitlik 3 ve 4'de $\mathrm{t}_{\mathrm{ij}}, \Pi_{\mathrm{i}}$, $\mathrm{P}_{\mathrm{j}}$ olarak belirtilen değişkenler çoklu ticaret direnci (Multilateral Trade Resistance

\footnotetext{
${ }^{3}$ Eşitlik 1'de belirtilen $X_{\mathrm{ij}}$ i ülkesinden $\mathrm{j}$ ülkesine ihracatın parasal değeri, $\mathrm{M}_{\mathrm{j}}$ ithalatçı talebinde belirleyici olan çeşitli faktörleri (ithalatçı ülke milli geliri, nüfus, vs), $S_{\mathrm{i}}$ ihracatçı arzında belirleyici olan çeşitli faktörleri (ihracatçı ülke milli geliri, nüfus, vs), G i ve j'ye bağlı olmayan faktörleri (dünya liberalizasyon seviyesi gibi) ve $\varnothing_{\mathrm{ij}}$ ise ihracatçının ithalatçı pazarına ulaşmadaki ticari maliyetleri temsil etmektedir. (i: ihracatçı ülke j: ithalatçı ülke)
} 
/MTR) olarak ifade edilen karşılıklı ticaret maliyetlerini temsil eden genel değişkenlerdir. MTR'nin alt bileşenleri olarak literatürde yer alan ticaret maliyetlerini belirleyici değiş̧enlerin daha net gösterimi Eşitlik 5'de verilmektedir.

$\mathrm{t}_{\mathrm{ij}}=d_{i j}^{\delta 1} \cdot \exp \left(\delta_{2}\right.$ cont $_{\mathrm{ij}}+\delta_{3} \operatorname{lang}_{\mathrm{ij}}+\delta_{4} \mathrm{ccol}_{\mathrm{ij}}+\delta_{5} \mathrm{col}_{\mathrm{ij}}+\delta_{6}$ landlock $_{\mathrm{ij}}+$ $\left.\delta_{7} \mathrm{RTA}_{\mathrm{ij}}\right) \ldots($ Eşitlik 5)

Ülkeler arasında artan mesafenin $\left(\mathrm{d}_{\mathrm{ij}}\right)$, transfer maliyetleri üzerinden ticaret maliyetini arttırdığı kabul edilmektedir. Ancak bunun dışında ilave değişkenlerde ayrıca kullanılmaktadır. Bunlar ilgili ülkelerin ortak sınır paylaşımı (cont $\mathrm{ij}_{\mathrm{ij}}$ ), ortak dil (lang $\mathrm{ij}_{\mathrm{j}}$ ), ortak koloni $\left(\mathrm{ccol}_{\mathrm{ij}}\right)$, ya da eskiden ortak bir koloninin parçası olmas1 $\left(\operatorname{col}_{i j}\right)$, ülkelerin birinin deniz veya kara parçaları ile çevrili olması (landlock $\mathrm{ij}_{\mathrm{ij}}$ ) ve ülkeler arasında bölgesel ticaret anlaşmasının olup olmaması şeklindeki yapay (dummy) değişkenler olarak tanımlanmaktadır. Ticaret maliyetleri ile ilgili kara veya denizle tamamen çevrili ülkelerde daha yüksek olduğu ve komşu ülkeler arasında daha düşük olduğu şeklinde görüşler bulunmaktadır. Ayrıca, ülkeler arasında ortak dil kullanımı ve geçmişi, komşu ülke ve ortak koloni olma ya da geçmişten gelen benzer paylaşımların varlı̆̆ının olup olmadığı şeklindeki diğer kültürel olgularda ticarette bilgi maliyetlerine etkileyeceği düşünülmektedir. Birbirlerini iş pratikleri, rekabet ve güven algıları açısından iyi tanıyan ülkeler arasında ticarette araştırma maliyetlerinin daha düşük olacağı beklenebilir. $\mathrm{Bu}$ olgu firmaların benzer ortamlarda faaliyet gösteren tedarikçi ya da müşteri firma aramaları ile de açıklanabilir. Dış ticaret politikasının bir aracı olarak tarifeler de çekim modeli çalışmalarında genellikle ülkeler arasındaki STA'nın varlı̆̆ şeklinde tanımlanan yapay değişken ile tanımlanmaktadır. Tarifelerin oransal ölçek olarak genellikle modelde kullanılmaması, geçmiş yıllara ait veri istatistiklerinin eksikliğinden kaynaklanmaktadır (WTO, 2012, s. 104-107).

Modelde belirtilen değişkenlerin zamansal değişimi dikkate alınarak denklem sistemi Eşitlik 6'da belirtildiği şekilde gösterilebilir. Çözümlemede genellikle panel veri regresyon modelleri sabit etkili (SE) veya rassal etkili (RE) yaklaşımlar ile kullanılmaktadır. Model katsayılarının tespitine yönelik farklı hesaplama yaklaşımları ayrıca literatürde yaygın tartışılmaktadır.

$\ln \mathrm{X}_{\mathrm{ij}}=\mathrm{a}_{0}+\mathrm{a}_{1} \mathrm{I}_{\mathrm{it}}+\mathrm{a}_{2} \mathrm{I}_{\mathrm{jt}}+\mathrm{a}_{3} \ln \mathrm{t}_{\mathrm{ijt}}+\mathrm{a}_{4} \mathrm{I}_{\mathrm{t}}+$ $\mathrm{u}_{\mathrm{ijt}} \ldots \ldots \ldots \ldots \ldots \ldots \ldots \ldots \ldots \ldots \ldots . . .($ Eşitlik 6$)$

$\left(\mathrm{I}_{\mathrm{i}}, \mathrm{I}_{\mathrm{j}}\right)$ : Ülkelere ait değişkenler $\left(\mathrm{t}_{\mathrm{ij}}\right)$ : ticaret maliyeti ile ilgili değişkenler

Çekim modeli ortaya atıldığı ilk dönemlerinde teorik temellerinin eksik olduğu gerekçesiyle eleştirilmiştir. Neticede Ricardo modelleri dış ticareti ülkeler arasındaki teknoloji farklılıkları, Heckscher-Ohlin modeli ise faktör donatımı ile açıklamaktaydı. Önerilen modelin ampirik olarak uluslarası ticareti açıklamada güçlü ve kararlı yapısı, teorik temellerinin güçlendirilmesine yönelik çalışmaları da beraberinde getirmiştir.

Anderson (1979) "Armington varsayımı" olarak tanımlanan ürünlerin menşeilerine göre farklılaşması ile her ülkenin fiyattan bağımsız olarak diğer ülkeler ile ticaret gerçekleştirdiği yönündeki çalışması ile çekim modelinin teorik temellerini güçlendirmeye çalışmıştır. Ayrıca, Bergstrand (1985 ve 1989) 
çalışmalarında, çekim modelinin Paul Krugman (1980) tarafından geliştirilen Tekelci Rekabet Modeli'nin doğrudan bir sonucu olduğunu göstermişlerdir. Ayrıca Deardorff (1998), çekim modelinin faktör oranları teorileri, Eaton ve Kortum (2002) ise Ricardo modeli ile açıklanabileceğini göstermiştir. Helpman ve diğerleri (2008) ve Chaney (2008) çalışmalarıda firma heterojenliği ile farklılaşmış ürünlerin uluslararası ticareti konusunda teorik temel sağlamaktadır. Modelin teorik temellerinin açıklanabilirliği açısından modelde kullanılan değişkenlerin önemi de ayrıca vurgulanmaktadır. Bu alanda, Anderson ve van Wincoop (2003) çalışmalarında, göreceli ticaret maliyet değişkenlerinin (Multilateral Trade Resistance /MTR) iyi tanımlanmış bir çekim modeli için önemini açıklamaktadırlar. Çekim modelini kullanarak iktisadi entegrasyon uygulamalarının etkilerini değerlendirmeye yönelik literatürde çeşitli çalışmalar mevcuttur. Urata ve diğerleri (2007), 178 ülke için 1950-2005 yılları arasındaki verileri ile çekim modeli çalışmalarında geniş kapsamlı olarak STA'ların ticaret yaratıcı ve saptırıcı etkilerini incelemişlerdir. Açıklayıcı değişken olarak ülkelerin milli geliri, kişi başına düşen milli gelir, ülkeler arası kişi başına düşen milli gelir farklarının mutlak değeri, mesafe, ortak sınır, ortak dil, STA varlığı gibi değişkenler seçilmiş ve değişken katsayılarının hesaplanmasında karma standart en küçük kareler (pooled ordinary least square/OLS), ağırlıklandırılmış standart en küçük kareler (weighted ordinary least square/OLSQ), ve genelleştirilmiş beklemler yöntem (generalized method of moments/GMM)'lerinden faydalanmış ve sabit etkiler altında analizler gerçekleştirilmiştir. Çalışmada daha önceden bu alanda gerçekleştirilmiş̧ literatürdeki geniş çaplı çalışma örnekleride yöntem ve sonuçlar bazında ayrıca yer almaktadır. Ülkelerin toplam dış ticaret akışları üzerinden gerçekleştirilen analiz sonuçlarına göre, birliklerin ticaret yaratıcı etkilerinin belirgin saptırıcı etkilerinin ise sınırlı olduğu sonucuna ulaşılmıştır. Ancak endüstriler bazında analizlerde sonuçlar farkl11ı göstermektedir. Yine Martinez-Zarzoso ve diğerleri (2009) dünya çapında inceledikleri bölgesel ticaret anlaşmalarının faydalarını değerlendirmede statik ve dinamik (zamansal etkili) çekim modelinden faydalanmışlardır. 1990 yılı sonrası yeni bir dalga olarak artan bölgesel iktisadi entegrasyon pratiklerinin gelişmekte olan ülkelere kıyasla gelişmiş ülkelere (AB, NAFTA) daha çok kazanım sağladığına dair dinamik model altındaki analiz sonuçları, istatistiksel olarak önemli ve kararlı (robust) niteliktedir. Statik nitelikli çekim modelinde ülkelerin dış ticaret akışlarının milli gelir ile zamansal etkisi dikkate alınmadığ 1 için bu etkiyi dikkate alan dinamik modelin önemi literatürde ayrıca vurgulanmaktadır (Bun \& Klaassen, 2002).

Babetskaia-Kukharchuk ve Maurel (2004) çalışmalarında çekim modelinden faydalanarak Rusya'nın DTÖ’ye üyeliğinin dış ticaret potansiyeli açısından anlamını incelemektedir. Modelde Anderson ve van Wincoop (2003) metodolojisinden faydalanılmış, ticaret maliyetlerini açıklamada mesafe yanında döviz kuru oynaklığı ve kurumsal değişkenler ayrıca kullanılmıştır. OLS, Rassal Etki ve Sabit Etki (Hausman-Taylor) yaklaşımları kullanılarak gerçekleştirilen analizlerin üçünde de daha iyi kurumsal kalitenin daha derin ekonomik 
entegrasyona neden olduğuna dair tek yönlü bir nedensellik tespit edilebilmiştir. Antonucci ve Manzocchi (2006) Türkiye'nin AB ile olan ticaret yapısını diğer ülkelerle karşılaştırmalı olarak çekim modeli ile incelemiştir. Çalışmanın özet olarak iki temel bulgusundan birincisi, Türkiye dış ticaretini açıklamada çekim modelinin iyi bir araç olduğu ve diğeri ise 1963 ortaklık anlaşması sonrasında 1996 yılında gümrük birliğinin devreye girmesine rağmen $\mathrm{AB}$ ve Türkiye arasında ilave bir ticaret gelişim etkisine yönelik bir kanıt bulunmamasıdır. Ülengin ve diğerleri (2015) çekim modeli ile kotaların Türkiye dış ticaretine etkilerini incelemişlerdir. Türkiye ihracatının bağımlı değişken olarak ilgili ülkeler toplam milli gelir, ülkelerin ölçek benzerliği, göreceli faktör donatım ölçüsü ve kota gibi bağımsız değişkenler ile modellendiği çalışmada parametrelerin hesaplanmasında sabit etkili model kullanılmıştır. Kotaların Türkiye tekstil ihracatındaki istatistiksel önemi tespit edilmiştir.

Genellikle ampirik çalışmalarda bağımlı değişken olarak, ülkelerin ihracat ve ithalat değerleri toplamı şeklinde dış ticaret göstergesi kullanıldı̆̆ı gibi aynı zamanda yalnızca ihracat veya ithalat değerleri üzerinden de model geliştirilmektedir. Bu şekilde ihracat ve ithalatın iki farklı denklemde farklı parametre katsayıları ile açıklanmaya çalışılmasının teorik uyum ve istatistiksel açıklanabilirliğin geliştirilmesi açısından daha iyi bir yaklaşım olabileceği düşünülmektedir (Dhar \& Panagariya, 1999, s. 11). Model katsayılarının tespitinde kullanılan veri kümelerinin doğruluğu ve kapsamı, sonuçları önemli ölçüde etkilemektedir (Cheptea, Gohin, \& Huchet-Bourdon, 2006). Ayrıca, sektörel olarak bir STA gibi dış ticaret politikası değişkeni altında ticaret yaratıcı ve saptırıcı etkilerin değerlendirilmesinde literatürde sektör bazlı olarak model geliştirme çalışmaları mevcuttur. (Urata \& Okabe, 2007, s. 1). Rose ve Wincoop (2001) ve Baldwin ve Taglioni (2006), çekim modeli katsayılarının ekonometrik hesaplamalarında, ülkesel sabit etki modellerinden faydalanmışlardır. Panel veri kullanımı ayrıca, farklı ülke heterojenliğinden kaynaklı olarak sapkılı (bias) ölçüm etkisinin giderilmesi açısından da avantajlıdır. Ancak çoklu ticaret direncini (MTR) temsil eden değişkenler arasındaki tam doğrusallık (perfect collinearity) sebebi ile sabit etki modelinin kullanılması uygun bir tercih olmayabilir. Bu nedenle rassal etkili modeller de tercih edilebilir. Hangi modelin tercih edilebileceğine yönelik Hausman testinden faydalanılmaktadır (WTO, 2012, s. 108). Veri kümesi içerisindeki sıfır ticaret verilerinin katsayı hesaplamalarında saptırıcı etkisinden dolayı regresyon ile değer üretme, logaritmik dönüşüm öncesi 1 gibi küçük bir değer tanımlama veya kesitin çıkarılması şeklinde farklı stratejiler belirtilmektedir (WTO, 2012, s. 112). Panel veri analizinde kullanılan sabit ve rassal etkili modellerden farklı olarak, Poisson maksimum olabilirlik modeli (PML) hem sifir ticaret verilerinin bozucu etkileri hem de değişen varyans (heteroscedasticity) varliğında güçlü sonuçlar verdiği Santos Silva ve Tenreyro (2006) ve Westerlund ve Wilhelmsson (2006) çalışmalarında açıklanmıştır. Değişen varyans açısından Poisson, Heckman ve Tobit modellerine alternatif olarak Xiong ve Chen (2012) tarafından TS-MM modeli önerilmiştir. 
Farklı ekonometrik yöntemler ile çözümlenebilecek olan çekim modelinin hangi koşul altında optimum sonuç verdiğine yönelik ampirik çalışmalar rassal panel veri üretimi konusunda yaygın olarak Monte $\mathrm{Carlo}^{4}$ simülasyonundan faydalanmaktadırlar. Anderson ve diğerleri (2004), Santos Silve ve diğerleri (2006), Westerlund ve diğerleri (2006), Cheptea ve diğerleri (2006), Xiong ve diğerleri (2012), Cipollina ve diğerleri (2013) ve Martin ve diğerleri (2015) çalışmalarında farklı metodolojilerin test edilmesinde Monte Carlo simülasyonunu kullanmışlardır. Heterojen panel veriler ile optimum öngörüleme yapılabilmek amaciyla Trapani ve Urga (2009) tarafından gerçekleştirilen Monte Carlo simülasyonu mevcut verilerin heterojenlik seviyesine bağlı olarak farklı yöntemsel yaklaşımları tanımlamaktadır.

\section{MODEL GELIŞTIIRME}

Çalışmada temel amaç, klasik bir STA varsayımı altında TTIP projesine Türkiye'nin dahil olması ve akabinde karşılıklı tarifelerin kaldırılması durumunda, Türkiye demir-çelik ihracatına olası etkiyi tahmin edebilmektir. Mevcut durumda $\mathrm{AB}$ ile Türkiye arasındaki tarife oranları zaten sıfır olduğu için (gümrük birliği sebebiyle) etkinin, daha çok $\mathrm{ABD}$ ile aradaki tarife oranları üzerinden irdelenmesi gerekmektedir. Tarifelerin ticaret maliyetini arttırarak karşılıklı ticareti azaltma şeklindeki kuramsal düşünceden yola çıkarak (Krugman \& Obstfeld, 2009, s. 185-186), Türkiye'nin projeye dahil olmasının demir-çelik ihracatını arttıracağı düşünülebilir. Çalışmadaki diğer bir odak noktası da TTIP etkisi ile küresel seviyede azalması beklenebilir olan tarifelerin (Lejour, Mustilli, Pelkmans, \& Timini, 2014), ülke grupları bazında Türkiye demir-çelik ihracatı açısından anlamını esas alınan model kapsamında irdelemektir. Ampirik analizlerde 172 ülkeye ait 1996-2014 yillarını $(\mathrm{t}=1996$, ...., 2014) kapsayan dengelenmiş panel (balanced panel) verileri kullanılmıştır. Modelde bağımlı değişsen $\left(X_{i t}\right)$ olarak Türkiye'nin ilgili ülkeye (i) demir-çelik ihracatının, Türkiye'nin milli gelir değerine olan oranı alınmıştır. Ticaret akışlarındaki bu şekildeki normalizasyonun reel ihracatı yakınsamaya yardımcı olduğu ifade edilmektedir (Antonucci \& Manzocchi, 2006). Bu şekilde ortak bir fiyat indirgeyicisi kullanımının daha rassal olacağı düşünülmektedir (Frankel \& Romer, 1999, s. 383). Analizlerde kullanilan ihracat verileri UNCOMTRADE veri tabanından alınmıştır. Modelde kullanılan açıklayıcı değişkenler seçilme gerekçeleri ve literatür referansları ile aşağıda açılklanmaktadır

*SUMGDP ${ }_{i t}$, ihracatçı ülke olarak Türkiye ve ithalatçı ülke milli gelirlerinin toplamının doğal logaritması olarak alınmış̧ır $\left(\mathrm{SUMGDP}_{\mathrm{it}}=\mathrm{ln}\right.$ $\left.\left(\mathrm{GDP}_{\mathrm{TRt}}+\mathrm{GDP}_{\mathrm{it}}\right)\right)$ ve ihracat akışlarına pozitif yönde etkisi olacağ

\footnotetext{
${ }^{4}$ Monte-Carlo simülasyon tekniği 1940 yllında Los Alamos Ulusal Laboratuvarında Manhattan Projesinde çalışan bir grup matematikçi tarafindan geliştirilmiştir. Yöntem, belirli bir istatistiksel dağılım dahilinde belirsiz değişkenlerin türetilmesine yönelik bilgisayar esaslı bir analitik yöntemdir.

Kaynak: Kroese, D.P., Taimre, T., Botev, Z.I., 2011, Handbook of Monte Carlo Methods (Wiley Series in Probability and Statistics), Wiley, Hoboken, NJ.

${ }^{5}$ Çözümlemede kullanılan yazılımların İngilizce karakter duyarlılıkları nedeniyle değişken kısa adları İngilizce ifadelerine uygun olarak model geliştirmede temel referans olan Antonucci ve diğerleri (2006)'nin değişken isimlerine benzer olarak seçilmiştir.
} 
düşünülmektedir (Antonucci \& Manzocchi, 2006). Milli gelir (GDP) değerleri, Dünya Bankası, WDI veri tabanından sağlanmıştır. ${ }^{*} S I M S I Z E_{i t}{ }^{6}$, Türkiye ve ihracat gerçekleştirilen ülke ekonomik ölçek benzerliğine dair bir ölçüdür. Değişkenin - (tam farklılık) ve -0,69 (tam benzerlik) arasında değer alması beklenir ve ticarete olan etkisi negatif yâda pozitif olabilecektir. Egger (2002)'in OECD ve AB ülkelerinin ikili ticaret akışlarını ve Antonucci ve diğerlerinin (2006) Türkiye AB ticaret yapısını incelemeye yönelik çalışmalarında değişkenin pozitif işaretli katsayısı tespit edilmiştir. Eğer ticaret akışları endüstriler arası (interindustry) nitelikte ise katsayının negatif olması beklenmektedir (Antonucci \& Manzocchi, 2006). ${ }^{*} \mathrm{RELENDOW}_{\mathrm{it}}{ }^{7}$, göreceli faktör donatımlarının bir ölçüsüdür. Linder etkisi olarak ifade edilen benzer talep yapısına sahip ülkelerin daha çok ticaret gerçekleştirebileceklerine dair görüş doğrultusunda modele ilave edilmiştir. Katsayının negatif işaretli olması endüstri içi (intraindustry) ticaret, pozitif işaretli olması ise endüstriler arası (interindustry) ticarete işaret etmektedir (Helpman E. , 1986, s. 76). Ülkelerin nüfuslarına (POP) dair veriler Penn Dünya Tablosundan (Versiyon 8.1) elde edilmiştir. *FTA ${ }_{i t}$, Türkiye'nin y1llar itibariyle ihracat gerçekleştirdiği ülke ile uygulamada olan STA varlığında 1, yokluğunda ise 0 değeri alan yapay değişkendir. Veriler TC. Ekonomi Bakanlığı web sitesinden elde edilmiştir. *TARIF $F_{\text {it, }}$ Türkiye'nin yllar itibariyle ihracat gerçekleştirdiği ülkelerde karşılaştı̆̆ı tarife oranlarını gösteren oransal ölçekli değişkendir. Tarifeler ad valorem olarak ihracatçının ithalatçı ülke pazarına ulaşım maliyetini arttıracağından ihracat miktarını negatif yönde etkileyeceği beklenmektedir. Ağırlıklı ortalama olarak tarife değerleri Dünya Bankası (WITS) veri tabanından sağlanmıştır. *DIST , Türkiye ile ihracata konu olan ülke arasındaki mesafenin logaritması şeklinde hesaplanan değişkendir. Veriler CEPII veri tabanından ülkelerin en kalabalık şehirleri arasındaki nispi mesafe olarak elde edilmiştir. *BORD , Türkiye ile ihracata konu olan ülke arasında kara veya deniz ortak sınırının olması durumunda 1, aksi durumda 0 değerini alan yapay değişkendir. Veriler CEPII veri tabanından alınmıştır. ${ }^{*} \mathrm{COL}_{\mathrm{i}}$, Türkiye ile ihracata konu olan ülke arasında geçmişten gelen ortak koloni birlikteliğinin var olması durumunda 1, aksi durumda 0 değeri alan yapay değişkendir. Veriler CEPII veri tabanından alınmıştır.

Bir önceki bölümde incelenen literatürdeki çekim modeli ile ilgili çalışmalarda belirtilen diğer değişsenler de ayrıca önemlidir. Özellikle döviz kuru oynaklı̆̆ının ihracata olan etkisi önemli bir değişken olabilir. Clark ve diğerlerinin (2004) IMF için gerçekleştirdiği döviz kuru oynaklıklarının ticaret akışlarına etkisini tespit etmeye yönelik ampirik çalışmada döviz kuru oynaklığındaki bir puan artışın istatistiksel olarak anlamlı seviyede \%7 civarında ticaret azalmasına neden olduğu tespit edilmiştir. Koç Yurtkur ve Tay

\footnotetext{
${ }^{6} \operatorname{SIMSIZE}_{\mathrm{ij}}=\ln \left[1-\left(\frac{G D P_{\mathrm{I}}}{G D P_{\mathrm{i}}+G D P_{J}}\right)^{2}-\left(\frac{G D P_{J}}{G D P_{\mathrm{i}}+G D P_{J}}\right)^{2}\right]$ Helpman ve Krugman (1985)

${ }^{7}$ RELENDOW $_{\mathrm{ij}}=\left(\ln \frac{G D P_{\mathrm{I}}}{P O P_{\mathrm{I}}}-\ln \frac{G D P_{J}}{P O P_{J}}\right)$
} 
Bayramoğlu (2012) çalışmasında Türkiye dahil gelişmekte olan ülkelerdeki reel döviz kurlarının ihracatta olan etkisinin önemi ölçülmektedir. Ancak 1996-2014 yılları arası Lira para birimi bazında ikili döviz kuru istatistiklerinin yetersiz olması sebebiyle açıklayıcı değişken olarak modele dâhil edilmemiştir. Ayrıca, genellikle çekim modeli literatür örneklerinde matematiksel denklem sistemi içerisinde nominal değerler kullanıldığ 1 için döviz kuru değişimleri ayrıca dikkate alınmamaktadır. Toplanan verilere panel veri regresyon yaklaşımı altında uygulanan Hausman test istatistiği sonucu modelde sabit etkili (SE) hesaplayıcı kullanımının daha anlamlı olduğunu ifade etmektedir ${ }^{8}$. Ayrıca panel verileri içerisinde zaman ile değişmeyen açıklayıcı değişkenlerin modelde yer alması ve bu değişkenler arasındaki göreceli yüksek korelasyon, model katsayıların sapkılı olarak hesaplanmasına neden olabilir. Örneğin, ülkeler arasındaki STA'nın varlığı karşılıklı yüksek ticaret hacminin de bir sonucu olabileceğinden, içsellik sapkısının (endogeneity bias) SE ile kontrol altına alınması sınırlı olabilir. Bu gerekçeler ile birlikte bağımsız değişkenlerin katsayılarının hesaplanmasında, Antonucci ve Manzocchi (2006) çalışmasından esas alınarak iki aşamalı eşitlik sistemi (Eşitlik 7 ve Eşitlik 8) kullanılmıştır. Panel veri regresyonunda genelleştirilmiş en küçük kareler (generalized least squares/GLS) prosedürü SE etkisi ile hesaplanan Eşitlik 7'deki sabit terimler $\left(\beta_{i}\right)$, Eşitlik 8 'de ülkeye özgü yapay değişken katsayılarının tespitinde bağımlı değişken olarak kullanılmıştır.

$\ln \mathrm{X}_{\mathrm{it}}=\beta_{\mathrm{i}}+\beta_{1}$ SUMGDP $_{\mathrm{it}}+\beta_{2}$ SIMSIZE $_{\mathrm{it}}+\beta_{3}$ RELENDOW $_{\mathrm{it}}+\beta_{4} \mathrm{FTA}_{\mathrm{it}}+$ $\beta_{5}$ TARIF $_{\text {it }}$

$\varepsilon_{\text {it. }}$

(Eşitlik 7)

$\beta_{\mathrm{i}}=\phi_{0}+\phi_{1} \mathrm{DIST}_{\mathrm{i}}+\phi_{2}$ BORD $_{\mathrm{i}}+\phi_{3} \mathrm{COL}_{\mathrm{i}}+\gamma_{\mathrm{i}}$ (Eşitlik 8)

Eşitlik 7 ile tanımlanan model statik bir modeldir. Yani karşılıklı ticaret geçmişinin bir sonraki dönemdeki etkisi dikkate alınmamaktadır. Ancak gerçekte faaliyet gösterilen ülkede gerçekleştirilen ticaretin gelecek yıllarda dağıtım ve hizmet altyapısı ile ilgili maliyetleri azaltacağı düşünülebilir. $\boldsymbol{A y \boldsymbol { y } \boldsymbol { } \boldsymbol { }}$ zamanda bahsedilen etkiden dolayı statik modellerdeki otokorelasyon sorunlart katsayı hesaplamalarınin sapkalı olmasina neden olabilecektir. $\mathrm{Bu}$ nedenle bağımlı değişkene ait bir dönem geçmiş verisinin $\left(\ln X_{\mathrm{it}-1}\right)$ açıklayıcı değişken olarak modele ilave edildiği dinamik modelleme yaklaşımlarında da faydalanılmıştır. Metot olarak genelleştirilmiş beklemler yöntemi (generalized method of moments/GMM) seçilmiştir. Dinamik panel veri analizinde, bağımlı değişkenin önceki dönem değerinin (lagged dependent variable) bağımsız

\footnotetext{
${ }^{8}$ Hausman Testi (R programı sonuçları)

phtest ()

data: Y (bağımlı değişken) $\sim \mathrm{X}$ (tüm bağımsız değişkenler)

chisq $=8729.3, \mathrm{df}=1, \mathrm{p}$-value $<2.2 \mathrm{e}-16$

alternative hypothesis: one model is inconsistent
} 
değişken olarak denklemin sağ tarafina ilave edilmesi, ekonometrik açıdan özellikle sabit etkiler yaklaşımı altında sapkılı (biased) tahmin etme problemini getirdiği iyi bilinmektedir. Bu sınıf içerisindeki tahmin edicilerin sapkısız (unbiased) tahmin etme şeklindeki performanslarının değerlendirildiği Behr (2003) çalışmasında, Blundell ve Bond tarafından önerilen GMM yaklaşımının etkinliği vurgulanmaktadır. Bölgesel ticaret anlaşmalarının faydalı olup olmadığını değerlendirmek üzere Martinez-Zarzoso (2009) çalışmasında dinamik panel veri analizinde yine aynı yaklaşımdan faydalanılmıştır. Bir beklem (moment), bir olasılık dağılımının beklenen değeri ve/veya varyansı gibi bir özet istatiğidir. " $Y_{i}=\beta_{1}+\beta_{2} X_{i}+u_{i}$ " şeklindeki bağlanım denkleminde " $\sum u_{i}$ $=0$ " ve " $\sum u_{i} X_{i}=0$ " sinırlamaları altında $\beta_{1}$ ve $\beta_{2}$ tahmin edicilerinin elde edilmesi benzerlik ilkesine dayandırılır. Bilinmeyen ana kütle katsayılarını tahmin eden benzerlik ilkesi ayrıca beklemler (moments) yöntemi olarak da bilinmektedir (Gujarati, ve diğerleri, 2012 s. 86). Bu temel yaklaşımın bir uzantısı olarak genelleştirilmiş beklemler yöntemi (GMM), değişen oynaklığa dayalı olması şeklindeki esnek varsayımları ile daha güvenilir tahminler verdiği ifade edilmektedir. Aç1k olarak maksimum-olabilirlik fonksiyonunun türetilmesinin zor olduğu durumlarda daha basit bir alternatif olarak bu yöntem önerilmektedir. Yöntemin temeli ortogonallik şartlarını kullanması ile tanımlanabilir ve özellikle büyük veri kümeleri için uygun olduğu belirtilmektedir (Behr, 2003 s. 4). Alternatiflerine kıyasla daha az ve zayıf varsayımları bulunmaktadır (Zsohar, 2012).

TTIP senaryolarına bağlı olarak STA (FTA) ve tarife (TARIF) değişkenleri direk olarak Türkiye diş ticaretini etkileyebilecektir. Bunun geliştirilen model ile belirli varsayımlar ve olasılıklar ile birlikte açıklanabileceği dikkate alınarak Monte-Carlo simülasyonu ile vaka türetme gerçekleştirilmiş ve sonuçlar raporlanmıştır (Şekil4). $\left(\beta_{4}, \mathrm{ss}_{4}\right)$ ve $\left(\beta_{5}, \mathrm{ss}_{5}\right)$ hesaplanan STA ve tarife değişkenlerine ait katsayıların ortalama değeri ve standart sapması, $(\Delta X)$ demirçelik ihracatındaki yüzde değişim miktarı olmak üzere farklı senaryoları değerlendirmedeki simülasyon uygulama denklemleri şu şekildedir:

a) Senaryo 1: TTIP devrede ve Türkiye sürece dahil $\left(\Delta X_{1}\right)$

$\mathrm{E}^{9}\left(\Delta \mathrm{X}_{1}, \quad \mathrm{ss}_{\mathrm{x} 1}\right)=\mathrm{RS}^{10}\left(\beta_{4}, \quad \mathrm{ss}_{4}\right) * \mathrm{FTA}+\mathrm{RS}\left(\beta_{5}\right.$,

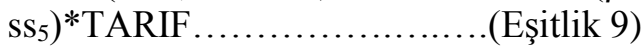

Dişsal değişken değerleri; FTA = 1 VE TARIF = 0 (ABD için)

b) Senaryo 2: TTIP'in küresel seviyede tarife azaltım etkisi $\left(\Delta \mathrm{X}_{2}\right)$

$\begin{array}{llll}\mathrm{E}\left(\Delta \mathrm{X}_{2},\right. & \left.\mathrm{sS}_{\mathrm{x} 2}\right) & = & \mathrm{RS}\left(\beta_{5},\right.\end{array}$

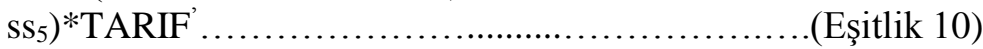

Dişsal değişken değerleri; TARIF' $=$ (Diğer ülke grupları için olası tarife değişimleri)

\footnotetext{
${ }^{9} \mathrm{E}()$--- Hesaplanan ihracat değişimlerinin dağılım fonksiyonu; beklenen değeri ve standart sapması ile tanımlı ${ }^{10} \mathrm{RS}($ ) - Rassal Sayı Üretim Fonksiyonu, 500 vaka türetilmiştir 


\section{ANALIZZ BULGULARI VE DEĞERLENDİRME}

Türkiye demir-çelik ihracatı 2014 yılı itibariyle yaklaşık 15 milyar dolar civarında olup, 1996-2014 yılları arasinda ortalama yıllık \%14.5 (mevcut \$) oranında büyüme göstermiştir (Miktar bazında \%6.5, Kaynak: Yazar Hesaplamaları). Ülke gruplarına yıllar itibariyle ihracat hacmindeki artış, en fazla MENA ve AB-EFTA grupları içerisinde gerçekleşmiştir (Şekil1). 2008 küresel krizin etkisi ile birlikte büyük miktarda azalan ihracat birçok ülke grubu içerisinde azalma eğilimine devam etmektedir. Uzakdoğu, Okyanusya, Hint Okyanusu ve Doğu Avrupa olarak sınıflandırılan gruplar içerisindeki ülkelere ihracat nispeten daha düşük seviyededir.

Şekil1. Demir Çelik İhracatının Ülke Gruplarına Göre Yıllar İtibariyle Değişimi
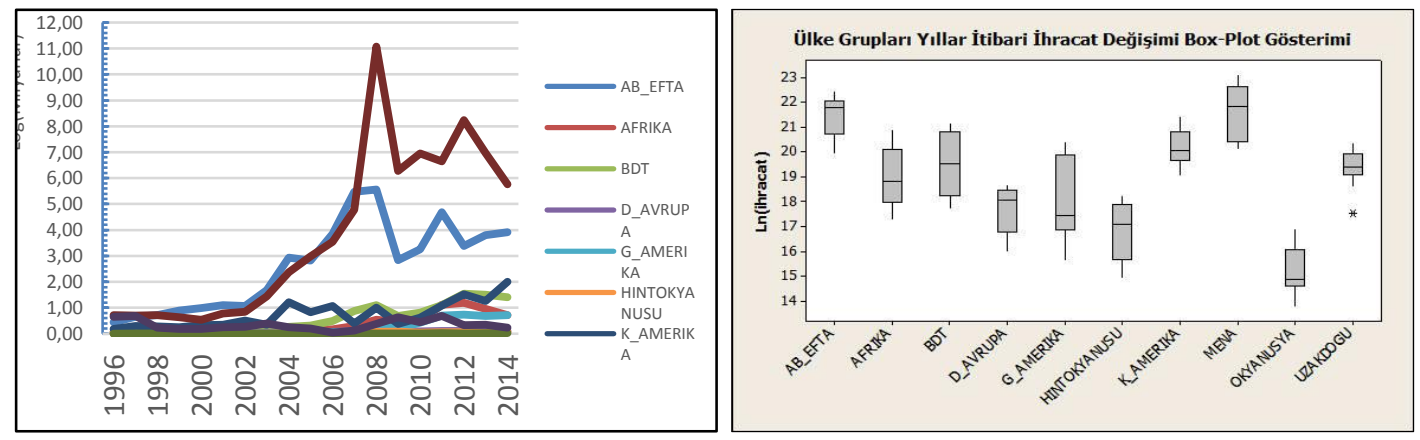

Şekil2. Demir Çelik İhracatında Ülke Gruplarına Göre Tarife Oranlarının Yıllar İtibariyle Değişimi

Dış ticaret politikası aracı olarak uygulanan tarife seviyelerine bakıldığında
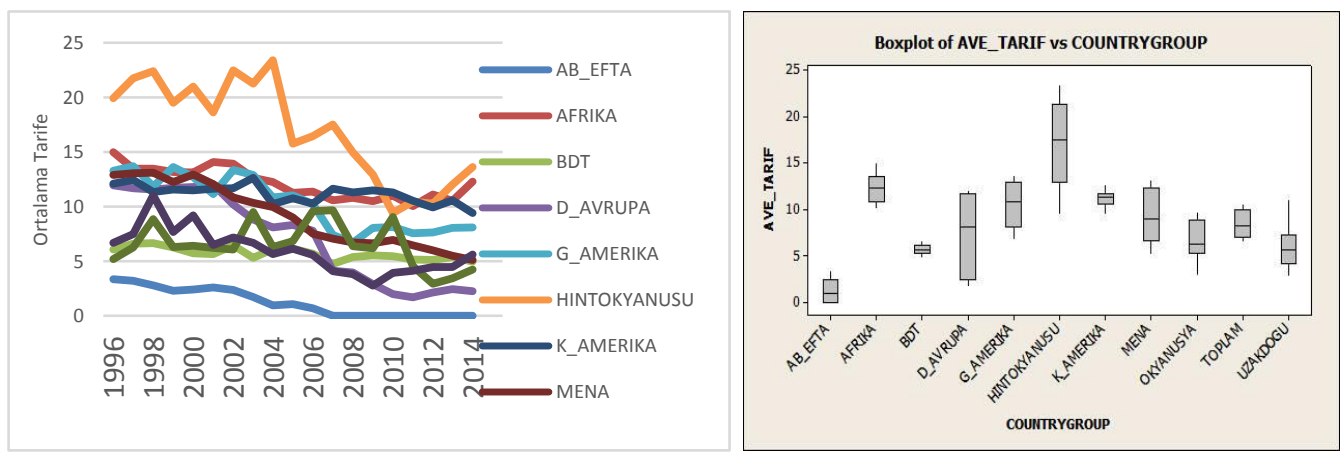

(Şekil2), yıllar itibariyle azalma eğilimi göstermektedir. Diğer ülkelere kıyasla Hint Okyanusu ülke grubunda korumacılık daha yüksektir. Gümrük Birliği sebebiyle AB ülkelerinde ortalama tarife oranları en düşük seviyededir. Kuzey Amerika ülke grubunda ise ortalama tarife oranı yaklaşık \%10 seviyesindedir. Demir çelik ihracatında HS kodu ile tanımlanan iki ana ürün grubu olan 72 (uzun ve yassı ürün grupları) ve 73 (boru, döküm vs. ürün grupları) nolu ürün gruplarına 
uygulanan tarife oranları incelendiğinde korumacilığın 73 nolu ürün grubunda daha yüksek olduğu görülmektedir. Ülke grupları her iki ürün grubunda birbirleri ile kıyaslandığında aynı sıralama da korumacılık özelliği göstermektedir. Türkiye'nin GB ve tercihli STA şeklinde uyguladığı dış ticaret politikalarının çelik ihracatı açısından durumuna bakıldığında, genel itibariyle arada ikili ticaret anlaşması olan ülkeler ile daha yüksek ihracat yapıldığı ifade edilebilir (Şekil3). Hem HS kodu olarak 2 dijitte ayrıştırılmış ürün grupları olarak hem de toplam ihracat olarak bakıldığında STA varlığında değerler daha yüksek olma eğilimi göstermektedir. Logaritmik ölçekte tüm ülke değerleri dikkate alınarak gerçekleştirilen ANOVA test sonucu Şekil3'de verilmiştir.

Tanımlanan temel modelin (Eşitlik 7 ve Eşitlik 8) R yazılımı kullanılarak çözümlenmesi sonucu hesaplanan katsayılar Tablo1 ve Tablo2'de verilmiştir. Ticaret akışlarında belirleyici bir unsur olarak öngörülen ülkelerin iktisadi büyüklüğünün bir göstergesi şeklindeki SUMGDP değişkenin katsayısı pozitif hesaplanmıştır. Daha yüksek milli gelire sahip ülkeler ile daha fazla ticaret gerçekleştirilmektedir. Ülkelerin ölçek benzerlikleri ile ilgili SIMSIZE değişkeninin katsayısı her iki hesaplama yaklaşımı altında değişen istatistiksel anlamlılık seviyesinde ancak pozitif olarak hesaplanmıştır.

Benzer talep yapılarında olan ülkelerin daha çok ticaret gerçekleştireceği şeklindeki görüş altında modele ilave edilen RELENDOW değişkeninin katsayısı hesaplama yaklaşımına bağlı olarak negatif ve pozitif olarak hesaplanmıştır. GMM yaklaşım altında, benzer iktisadi ölçek ve faktör donatımına sahip ülkeler ile daha fazla ticaret gerçekleştirilmektedir. Mesafe ile ilgili değişken (DIST) katsayısı da istatistiksel olarak anlamlı ve beklenildiği şekilde negatif olarak hesaplanmıştır. Yakın bölgelere uzak bölgelere kıyasla daha fazla ihracat gerçekleştirilmektedir.

Şekil3. Türkiye'nin STA Varlığı (1) yâda Yokluğu (0) Altında İhracat

Seviyelerindeki Farklılık (Logaritmik Ölçek)

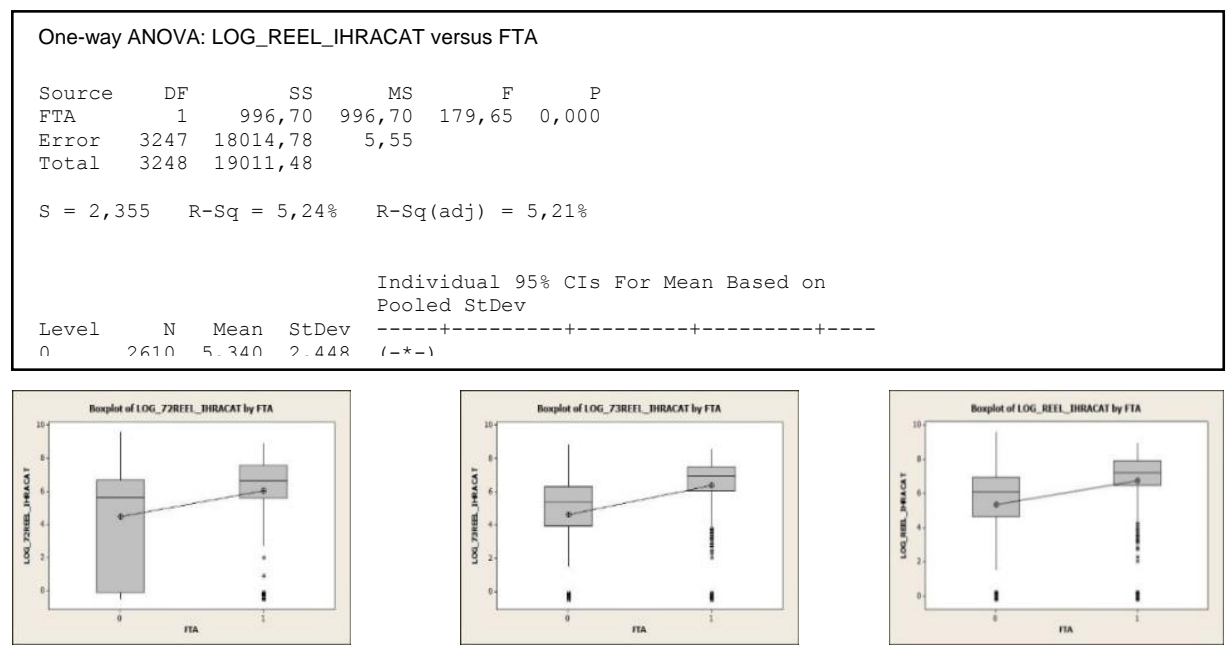


Tablo1. Türkiye Demir-Çelik İhracatı için Panel Veri Regresyon Sonuçları

\begin{tabular}{|c|c|c|c|}
\hline \multirow[b]{2}{*}{ DEĞİŞKENLER } & \multicolumn{3}{|c|}{ HESAPLAMA YÖNTEMLERİ } \\
\hline & GLS-SE & GLS-RE & GMM \\
\hline $\operatorname{Ln} X_{\mathrm{it}-1}$ & & & $-1.380(* * *)$ \\
\hline SUMGDP & $1.907(* * *)$ & $1.632(* * *)$ & $1.566(*)$ \\
\hline SIMSIZE & $0.659(0.155)$ & $1.510(* * *)$ & $2.329(* * *)$ \\
\hline RELENDOW & $-1.101(* *)$ & $0.305(*)$ & $0.699(* *)$ \\
\hline FTA & $-0.516(0.134)$ & $-0.251(0.402)$ & $0.153(0.715)$ \\
\hline TARIF & $-0.052(* * *)$ & $-0.055(* * *)$ & $-0.097(* *)$ \\
\hline Sabit Terim & - & $-52.535(* * *)$ & - \\
\hline \multicolumn{4}{|c|}{$\begin{array}{l}\text { Hesaplanan katsayıların p-değerleri } * * *(0), * *(0.001), *(0.01) \text { olarak belirtilmiş ve } \\
\text { istatistiksel anlamsız olanların değerleri yazılmıştır. }\end{array}$} \\
\hline $\mathrm{R}^{2}$ & 0.740 & 0.371 & \multirow{4}{*}{$\begin{array}{l}\text { Sargan Test }: p= \\
0.00043657 \\
\text { Otokorelasyon test }(1): p= \\
0.251 \\
\text { Otokorelasyon test }(2): p= \\
0.014 \\
\text { Katsayılar için wald test }: p \\
=\sim 0 \\
\text { Zamansal yapay } \\
\text { değişkenler için wald test: } p \\
=\sim 0\end{array}$} \\
\hline Hausman Testi $^{11}$ & 30.465 & 30.465 & \\
\hline $\begin{array}{l}\text { Breusch- } \\
\text { Godfrey/Wooldridge } \\
\text { Testi }^{12}\end{array}$ & 471.26 & - & \\
\hline $\begin{array}{l}\text { Wooldridge İlk-Fark } \\
\text { Testi }^{13}\end{array}$ & 16.867 & - & \\
\hline $\begin{array}{l}\text { Dickey-Fuller }{ }^{14} \\
\text { (Birim Kök) }\end{array}$ & $\begin{array}{l}-13.061 \\
P=0.01\end{array}$ & - & \\
\hline
\end{tabular}

Tablo2. Türkiye Demir-Çelik İhracatı için Yatay Kesit Regresyon Sonuçları (Eşit.8)

\begin{tabular}{|c|c|}
\hline DEĞİSKENLER & \\
\hline SABİT $\left(\phi_{0}\right)$ & $-48.781(* * *)$ \\
\hline DIST & $-1.565(* * *)$ \\
\hline BORD & $1.669(0.320)$ \\
\hline COL & $-0.118(0.929)$ \\
\hline \multicolumn{2}{|c|}{$\begin{array}{c}\text { Hesaplanan katsayıların p-değerleri } * * *(0), * *(0.001), *(0.01) \text { olarak belirtilmiş ve istatistiksel } \\
\text { anlamsız olanların değerleri yazılmıştır. }\end{array}$} \\
\hline R2 & 0.125 \\
\hline DIST:BORD & ANOVA (p: 0.418) \\
\hline DIST:COL & ANOVA (p: 0.234) \\
\hline BORD:COL & ANOVA (p: 0.274$)$ \\
\hline
\end{tabular}

Çalışmanın temel odak noktasını oluşturan FTA değişkeni katsayısı GLSSE hesaplama yaklaşımı altında negatif ancak GMM modeli altında pozitif olarak hesaplanmıştır. Hesaplanan değerler istatistiksel olarak anlamlı değildir. Tarife ile ilgili değişken katsayısı ise istatistiksel olarak anlamlı ve negatif

\footnotetext{
${ }^{11}$ phtest (SE, RE), sabit etkili model seçimi anlamlı

${ }_{12}$ pbgtest(SE, order=2), seri korelasyon mevcut

${ }_{13}$ pwfdtest(), ilk fark alarak kullanım seri korelasyon için anlamlı

14 adf.test $(X, k=2)$, birim kök bulunmamakta yani bağımlı değişken veri serisi durağandır
} 
olarak hesaplanmıştır. Yüksek tarife uygulanan bölgelerde düşük tarife uygulananlara kıyasla daha az ihracat gerçekleştirilmiştir. GMM yaklaşımı altında bağımlı değişkenin bir dönem önceki değerinin açıklayıcı değişken olarak ilave edilmesiyle otokorelasyon sebebiyle sapkılı katsayı hesaplama riski azaltılmıştır. Ancak ihracatın bir önceki dönem değeri mevcut döneme etkisinde istatistiksel olarak anlamlı ve negatif bir katsayı hesaplanmıştır. Milli gelirde demir-çelik ihracatının oranının bir önceki yıl değeri yüksek olan yıllarda düşük olan yıllara kıyasla daha az ihracat gerçekleştirilmiştir. Analizlerde tespit edilen tarife (TARIF) ve STA (FTA) açıklayıcı değişken katsayıları ortalama değeri ve standart sapmaları simülasyon uygulamasındaki rassal sayı üretiminde kullanılmıştır. İstatistiksel anlamlılık seviyeleri dikkate alınarak dinamik model (GMM) hesaplama yaklaşımındaki katsayı değerleri dikkate alınmıştır. Demirçelik ihracat değişimi ile ilgili Eşitlik 9 ve 10 uyarınca gerçekleştirilen MonteCarlo simülasyon uygulama sonuçları Şekil4’ de özetlenmiştir.

Şekil 4. Simülasyon Sonuçları (Yazar Hesaplamaları): Demir-Çelik İhracat Değiş̧im Yüzdesi Dağılımı (ABD ile STA Kurulması ve Tarife Giderimi (a), Diğer ülke grupları için ortalama \%1 tarife azalışı (b))
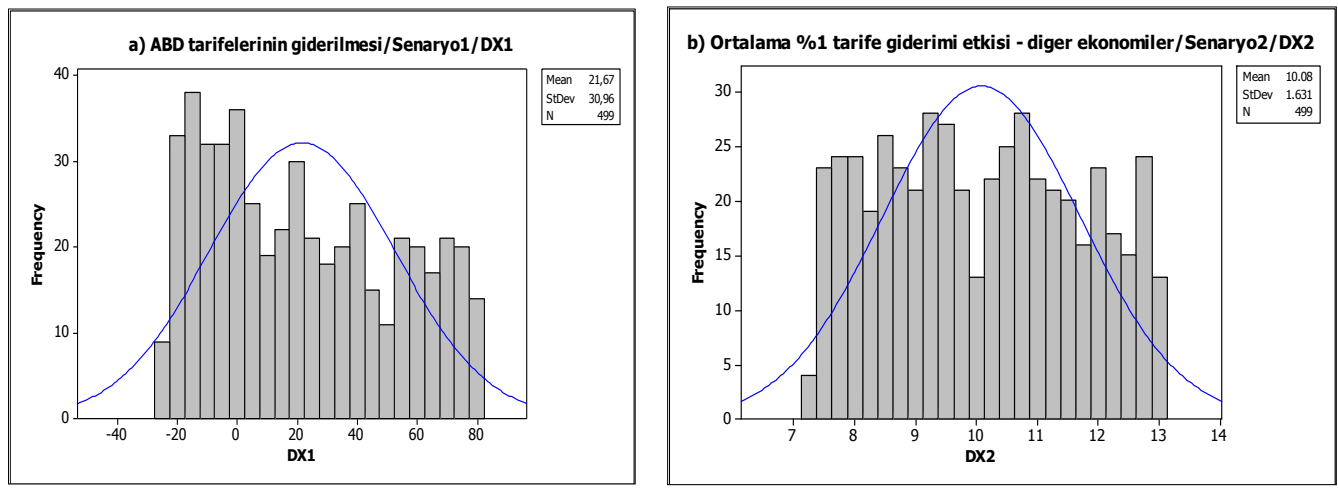

\section{SONUÇLAR VE ÖNERILLER}

Bölgesel iktisadi entegrasyon uygulamalarının yoğunlaştığı günümüzde, bu güne kadarki en kapsamlı girişim olan $A B$ ve ABD arasındaki TTIP projesinin, dünya ülke ekonomilerine doğrudan ve dolaylı etkileri tartışıla gelmektedir. TTIP'in dünya genelindeki makroekonomik etkilerini değerlendirmeye yönelik farklı literatür kaynaklarında farklı değerlendirme sonuçlarına ulaşılmaktadır. Beklenen makro ekonomik etkilerden yola çıkarak küresel dış ticaret akışlarındaki değişimleri de ampirik olarak değerlendirmek, iktisat ve uluslararası ticaret teorileri 1şığında mümkün hale gelebilmektedir.

TTIP etkisini değerlendirmeye yönelik uluslararası ve ulusal literatürde yer alan benzer çalışmalar genellikle GTAP metodolojisine dayalı olarak genel denge analizinden faydalanmaktadır. Çalışmaların genel odak noktası tek bir endüstri etkilerinden öte diş ticaret politika değişkenlerinin yarattığı zincirleme etkiler, genel ekonomi dengesi, makroekonomik etkilerdir. Bu yöntem ile analizlerin 
güvenilirliği güncel veri kullanımına önemli seviyede duyarlı olması ve araştırma dönemi içerisinde Türkiye için güncel girdi-çıktı tablosunun mevcut olmaması gibi sebeplerden dolayı bu çalışmada literatür örneklerinden farklı olarak çekim modeli ve ekonometrik analiz tercih edilmiştir. Burada odak noktası demir-çelik olarak seçilen tek bir endüstrinin ihracat akışlarıdır. Tarife değişkenlerinin elde edilmesinde literatürde yer alan çalışmalar ile benzer veri kaynaklarından faydalanılmıştır. Ekonometrik model olarak tahmin edicilerin hem statik hem de dinamik model sonuçları birlikte raporlanmıştır. Çalışmadaki ekonometrik temelli analiz yaklaşımı özellikle etki değerlendirmenin olasılık dahilinde irdelenmesine imkan sağlamıştır. Literatürde yaygın olarak uygulama sonrası (ex-post) etki değerlendirmede tercih edilen çekim modeli bu çalı̧̧ma kapsamında ön etki değerlendirme (ex-ante) de kullanılmakta ve bulgular simülasyon sonuçları ile birlikte verilmektedir.

$\mathrm{Bu}$ çalışma ile sektörel bazlı olarak Türkiye demir-çelik ihracatının dış ticaret politikasının araçları olarak STA ve tarife değişkenlerine olan duyarlılıkları hesaplanmıştır. Statik ve dinamik tahmin ediciler ile birlikte tarife değişkeninin katsayısı negatif olarak tespit edilmiştir. Bu durum tarife azalımlarının ihracatı arttırma şeklinde bir sonuç yaratacağ 1 beklentisini desteklemektedir. Hesaplanan duyarlılıklar dikkate alınarak TTIP'in getireceği ABD ile aradaki yeni STA mevcudiyeti ve tarifelerin giderilmesi durumlarına göre demir-çelik ihracatındaki öngörülen değişimler simülasyon uygulaması ile türetilmiştir.

TTIP projesinin yalnızca tarifeler açısından Türkiye demir-çelik ihracatı için anlamı, son y1llarda ABD'nin uyguladığ ortalama \%0. 09 seviyesinde tarifelerin giderilmesi şeklindedir ( $\mathrm{AB}$ için hali hazırda sıfır tarifeler). Ayrıca, FTA kurulumunun karşılıklı ticaret akışlarında bir ivme yaratacağı beklenebilir. Her iki etki altında demir-çelik ihracatında simülasyon sonucuna göre yaklaşık $\% 18^{15}$ ile $\% 24^{16}$ değişim anlamına gelmektedir. Buradan TTIP'in Türkiye'ninde sürece dahil olma yönünde bir senaryo (veya $\mathrm{ABD}$ ile Türkiye arasında STA kurulması) ile ilerlemesi durumunda, demir çelik ihracatının artacağ 1 sonucuna ulaşılmaktadır. TTIP'in küresel seviyede yaratabileceği tarife azalım etkisinden de bahsedilebilir. Analiz sonuçlarına göre, yalnızca tarifelerin \%1 azaltılmasının demir çelik ihracatı açısından ortalama \%10.08 olarak değişim yaratması hesaplanmıştır. Dolayısıyla, TTIP'in yalnızca tarife etkilerinin dikkate alındığı bu çalışma ile projenin uygulamaya geçmesinin $\mathrm{ABD}$ dışı diğer dünya ülkelerine demir çelik ihracatı açısından da artış sağlanabileceği sonucuna ulaşılabilir. Türkiye'nin projeye taraf olması durumunda ihracatta beklenen artış daha yüksek olabilecektir. Kısmi denge analizi yaklaşımı altında demir-çelik ihracatının miktar olarak fiyat duyarlılığı -1.19 olarak tespit edilmiştir (Yazar Hesaplaması, miktar ve fiyat logaritmik eksende).

TTIP'in ülke ekonomilerinde yaratması beklenen milli gelir değişimleri de ayrıca demir çelik ihracatı açısından dikkate alınabilir bir faktördür. Hem Türkiye

\footnotetext{
${ }^{15}(21.67-2 * 30.96 \sqrt{500}) \% 95$ güven alt sınır değeri

${ }^{16}(21.67+2 * 30.96 \sqrt{500}) \% 95$ güven üst sınır değeri
} 
hem de ihracata konu olan ülke milli gelirleri çalışmada çeşitli bağımsız değişkenler ile birlikte tanımlandığı dikkate alındığında, TTIP'in yaratacağı milli gelir değişimlerinin ihracat açısından değerlendirilmesi bu çalışma kapsamı dışında tutulmuştur. Güncel girdi-çıktı tabloları kullanılarak gerçekleştirilecek genel denge analizleri dikkate alınarak çalışmanın gelecekte bu kapsamda da değerlendirilmesi önerilebilir. Özellikle, Türkiye'nin TTIP'e taraf olmama senaryosunun irdelenmesinde bu araştırma önerisi kullanılabilecektir.

Tarife veya TDE şeklindeki fiyat artışına neden olabilecek etkenlerin STA'lar ile birlikte azaltılmasının ihracatı artırması beklenebilir. Ancak AB ve ABD'nin ihracatta Türkiye'ye uyguladıkları tarife oranlarına bakıldığında sıfıra oldukça yakın bir seviyededir. Bu bağlamda Türkiye'nin projeye dahil olma durumu demir-çelik ihracatı açısından irdelemek oldukça sınırlı bir bakış sunmaktadır. Bu nedenle projenin etkilerini değerlendirmede, küresel seviyede değişim yaratacağı düşünülen milli gelir ve diğer ekonomilerin uyguladıkları tarife seviyeleri üzerinden de bakılmaya çalışılmalıdır. Berumet ve diğerleri (2014), Türkiye ihracatının, ihracata konu ülke ekonomilerindeki büyümeye olan duyarlılıklarını ölçümlemeye çalışmış ve istatistiksel olarak anlamlı sonuçlar elde edebilmiştir.

TTIP ile birlikte tarife dışı engellerin kaldırılmasının etkisi de önemli bir unsurdur. Ancak söz konusu engellerin gerek ölçümüne gerekse de geçmişe yönelik sistematik istatistiklerin yeterli olmayışı sebebiyle çalışmada dikkate alınmamıştır. $\mathrm{Bu}$ doğrultuda model ilerleyen çalışmalarda bu doğrultuda geliştirilebilir.

\section{KAYNAKÇA}

Akman M. Sait AB-ABD Transatlantik Ticaret ve Yatırım Ortaklığı: Türkiye Açısından Bir Değerlendirme [Dergi] // Ankara Avrupa Çalışmaları Dergisi. - 2014. - s. Cilt:13, No:1, 129.

Akman Sait, Evenett Simon J. ve Low Patrick Catalyst? TTIP's Impact on the Rest [Rapor]. London, UK : Centre for Economic Policy Research-TEPAV, 2015.

Anderson J A theoretical foundation of the gravity model [Dergi]. - [basim yeri bilinmiyor] : American Economy Review, 1979. - 106-116 : Cilt 69.

Anderson J.E. ve van Wincoop E. Gravity with gravitas: a solution to the border puzzle [Dergi]. [basım yeri bilinmiyor] : American Economic Review 93: 170-92, 2003.

Anderson Michael A. ve Ferrantino Michael J. Monte Carlos Appraisals of Gravity Model Specifications [Dergi]. - [basim yeri bilinmiyor] : U.S. International Trade Commision, Office of Economics Working Paper, 2004. - No. 2004-05-A.

Antonucci Daniele ve Manzocchi Stefano Does Turkey have a special trade relation wtih the EU? A gravity model approach [Dergi] // Economic Systems 30. - 2006. - s. 157-169.

Arellano M. Panel Data Econometrics [Kitap]. - Oxford : Oxford University Press, 2003.

Arita Shawn, Beckman Jayson ve Mitchell Lorraine Reducing transatlantic barriers on U.S.-EU agri-food trade: What are the possible gains? [Dergi] // Food Policy 68. - 2017. - s. 233-247.

Babetskaia-Kukharchuk Oxana ve Maurel Mathilde Russia's accession to the WTO: the potential for trade increase [Dergi]. - [basım yeri bilinmiyor] : Journal of Comparative Economics 32 (2004) 680-699, 2004.

Baldwin R. ve Taglioni D. Gravity for dummies and dummies for gravity equations [Dergi]. [basim yeri bilinmiyor] : National Bureau of Economic Research Working Paper 12516, NBER, 2006.

Beer Elisabeth [ve diğerleri] The Consequences of TTIP for employees [Rapor]. - [basım yeri bilinmiyor] : FEPS Policy Brief, 2016. 
Behr Andreas A comparison of dynamic panel data estimators: Monte Carlo evidence and an application to the investment function [Dergi] // Discussion paper 05/03 Economic Research Centre of the Deutsche Bundesbank. - 2003.

Berden Koen G. [ve diğerleri] Non-Tariff Measures in EU-US Trade and Investment - An Economic Analysis [Rapor]. - Rotterdam : ECORYS Nederland BV, 2009.

Bergstrand J. H. The generalized gravity equation, monopolistic competition and the factorproportions theory in international trade [Dergi]. - [basim yeri bilinmiyor] : The Review of Economics and Statistics 71(1):143-53, 1989.

Bergstrand J. H. The gravity equation in international trade: some microeconomic foundations and empirical evidence [Dergi]. - [basım yeri bilinmiyor]: The Review of Economics and Statistics 67(3): 474-81, 1985.

Berument M. Hakan, Dincer N. Nergiz ve Mustafaoglu Zafer External income shocks and Turkish exports: A sectoral analysis [Dergi]. - [basim yeri bilinmiyor] : Economic Modelling 37, 476-484, 2014.

Brakman Steven, Kohl Tristan ve Marrewijk Charles Van The Impact of the Transatlantic Trade\&Investment Partnership (TTIP) on Low Income Countries: Agreement heterogeneity and supply chain linkages [Rapor]. - The Netherlands : The Directorate for Trade Policy and International Economic Governance, the Ministry of Foreign Affairs, 2015.

Bun Maurice J.G. ve Klaassen Franc J.G.M. The Importance of Dynamics in Panel Gravity Models of Trade [Dergi]. - [basım yeri bilinmiyor] : University of Amsterdam, 2002.

Buongiorno Joseph [ve diğerleri] Potential impact of a Transatlantic Trade and Investment Partnership on the global forest sector [Dergi] // Journal of Forest Economics 20. - 2014. - s. 252-266.

Cai Songfeng, Zhang Yaxiong ve Meng Bo Spillover Effects of TTIP on BRICS Economies: A Dynamic GVS-Based CGE Model [Rapor]. - Chiba, Japan: Institute of Developing Economies, JETRO, 2015.

Capaldo Jeronim The Trans-Atlantic Trade and Investment Partnership: European Disintegration, Unemployment and Instability [Dergi]. - Melford, USA: Global Development and Environment Institute, 2014. - Cilt Working Paper No. 14-03.

Chaney T. Distorted gravity: the intensive and extensive margins of international trade [Dergi]. [basım yeri bilinmiyor] : American Economic Review 98: 1707-21, 2008.

Cheptea A., Gohin A. ve Huchet-Bourdon Maryline Applying the gravity approach to sector trade: who bears the trade costs? [Dergi] // 2emes journees de recherches en sciences sociales / INRA SFER CIRAD. - 2006.

Cipollina Maria [ve diğerleri] A Note on Dummies For Policies in Gravity Models: A Monte Carlo Experiment [Dergi]. - [basım yeri bilinmiyor] : Dipartimento di Economia Università degli studi Roma Tre, 2013. - Cilt ISSN 2279-6916 Working papers n 180.

Clark Peter [ve diğerleri] Exchange Rate Volatility and Trade Flows-Some New Evidence [Dergi]. [basım yeri bilinmiyor] : IMF, 2004.

Czarny E. ve Folfas P. World Trade and Regional Trade Orientation in the Contxt of Forthcoming Transatlantic Trade and Investment Partnership [Dergi] // Equilibrium. Quarterly Journal of Economics and Economic Policy 10(3). - 2015. - s. 105-128.

Çeştepe Hamza ve Mıstaçoğlu Tuğba Gelişmekte Olan Ülkelerde Doğrudan Yabancı Yatırımlar ve Ekonomik Entegrasyon: ASEAN ve MERCOSUR Örneği [Dergi] // Yönetim ve Ekonomi Cilt: 17 Sayı:2. - 2010. - s. 93-106.

Deardorff A.V. Determinants of bilateral trade: does gravity work in a neoclasical world? [Dergi]. Chicago and London: The Regionalization of the World Economy. University of Chicago Press, 1998. - 7-32.

Deloitte The Iron and Steel Industry in Turkey [Rapor]. - Ankara: Investment Support and Promotion Agency of Turkey, 2013.

Dhar S. ve Panagariya A. Is East Asia Less Open than North America and the EEC? No. [Dergi] // International Trade Policy and the Pacific Rim. - 1999. 
Dobrea Razvan Catalin, Podgoreanu Iulia Xenia ve Borisov Daniela Liliana The Impact of Transatlantic Trade and Investment Partnership on the European Eco-Innovation [Dergi] // Procedia Economics and Finance 27. - 2015. - s. 659-668.

Eaton J. ve Kortum S. Technology, geography and trade [Dergi]. - [basım yeri bilinmiyor] : Econometrica 70: 1741-79, 2002.

ECORYS Impact Assessment of TTIP for Belgium [Rapor]. - [basım yeri bilinmiyor] : Ecorys Nederland BV, University of Bern, Worl Trade Institute, Cambridge Econometrics, IDEA Consult NV, 2016.

ECORYS Trade Sustainability Impact Assessment on the Transatlantic Trade and Investment Partnership (TTIP) between the European Union and the United States of America [Rapor]. - Rotterdam : ECORYS Nederland BV, 2014.

Egger Peter [ve diğerleri] Non-Tariff Barriers, Integration and the Trans-Atlantic Economy [Rapor]. - [basım yeri bilinmiyor] : Oxford Economic Policy, 2014.

Egger Peter An Econometric View on the Estimation of Gravity Models and the Calculation of Trade Potentials [Dergi]. - Oxford, UK : Blackwell Publishers Ltd, 2002.

Erixon Fredrik ve Bauer Matthias A Transatlantic Zero Agreement: Estimating the Gains from Transatlantic Free Trade in Goods [Rapor]. - Brussels, Belgium : ECIPE Occasional Paper, No. 4/2010, 2010.

Federal Environment Agency Environmental protection under TTIP [Rapor]. - Germany : Unwelt Bundesamt, 2015.

Feenstra R. Advanced International Trade [Kitap]. - [basım yeri bilinmiyor] : MIT Press, 2004.

Felbermayr Gabriel [ve diğerleri] Dimensions and Effects of a Transatlantic Free Trade Agreement Between the EU and US [Rapor]. - Munich : ifo Institut-International Trade Department, 2013.

Felbermayr Gabriel [ve diğerleri] Macroeconomic potentials of transatlantic free trade: A high resolution perspective for Europe and the world [Konferans] // Economic Policy Sixtieth Panel Meeting Hosted by the Einaudi Institute for Economics and Finance (EIEF). - Rome : [yazarı bilinmiyor], 2014.

Felbermayr Gabriel [ve diğerleri] Potential impacts of the Transatlantic Trade and Investment Partnership (TTIP) on developing and emerging economies [Rapor]. - München : Ifo Center for International Economics, 2015.

Felbermayr Gabriel, Heid Benedikt ve Larch Mario TTIP: Small Gains, High Risks? [Dergi] // CESifo Forum 4. - 2014.

Felbermayr Gabriel, Heid Benedikt ve Lehwald Sybille Transatlantic Free Trade: Winners, Losers and Necessary Accompanying Measures [Dergi]. - [basim yeri bilinmiyor]: Law and Business Review of the Americas, 2013.

Felbermayr Gabriel, Heid Benedikt ve Lehwald Sybille Transatlantic Trade and Investment Partnership (TTIP): Who benefits from a free trade deal? [Rapor]. - Munchen : Bertelsmann Stiftung, 2013.

Fontagne Lionel, Gourdon Julien ve Jean Sebastien Transatlantic Trade: Whither Partnership, Which Economic Consequences? [Dergi]. - [basim yeri bilinmiyor] : Policy Brief CEPII, 2013.

Francois Joseph [ve diğerleri] Reducing Trans-Atlantic Barriers to Trade and Investment [Rapor]. London, UK : Centre for Economic Policy Research, 2013.

Frankel Jeffrey A. ve Romer David Does Trade Cause Growth? [Dergi]. - [basım yeri bilinmiyor] : The American Economic Review, 1999. - No.3 s.379-399 : Cilt Vo.89.

Freytag Andreas, Draper Peter ve Fricke Susanne The Impact of TTIP, Volume 1: Economic Effects on the Transatlantic Partners, Third Countries and The Global Trade Order [Rapor]. Berlin : Konrad-Adenauer-Stiftung e.V, 2014.

Gostomski Eugeniusz ve Michalowski Tomasz Negotiations on the Transatlantic Free Trade Area. Effects of the Proposed Agreement on the Economies of the European Union and the United States of America [Dergi] // European Integration Studies. - 2015/9. - s. 127-138.

Greenaway David ve Milner Chris Regionalism and Gravity [Rapor]. - The University of Nottingham : Leverhulme Centre for Research on Globalisation and Economic Policy, 2002. 
Gujarati Damodar N. ve Porter Dawn C. Temel Ekonometri [Kitap]. - İstanbul : Literatür Yayınları: 656; Çevirenler: Ümit Şenesen, Gülay Günlük Şenesen, 2012.

Güneş Didem, Mavuş Merve ve Oduncu Arif AB-ABD Serbest Ticaret Anlaşması ve Türkiye Üzerine Etkileri [Dergi] // Türkiye Cumhuriyeti Merkez Bankas1. - 2013. - s. Say1: 2013-30.

Hamilton Daniel S. ve Quinlan Joseph P. The Transatlantic Economy 2015: Annual Survey of Jobs, Trade and Investment between the United States and Europe [Rapor]. - Washington, DC: Center for Transatlantic Relations, 2015. - s. 1.

Helpman E. ve Krugman P.R. Market Structure and Foreign Trade [Dergi]. - Cambridge : MIT Press, 1985.

Helpman E., Melitz M. ve Rubinstein Y. Trading partners and trade volumes [Dergi]. - [basım yeri bilinmiyor] : Quarterly Journal of Economics 123: 441-87, 2008.

Helpman Elhanan Imperfect Competition and International Trade: Evidence from Fourteen Industrial Countries [Dergi]. - [basim yeri bilinmiyor]: Journal of the Japanese and International Economies, 1986. - 62-81 : Cilt 1.

Hertel Thomas [ve diğerleri] How confident can we be of CGE-based assessments of Free Trade Agreements? [Dergi] // Economic Modeling 24. - 2007. - s. 611-635.

Hilary John The Transatlantic Trade and Investment Partnership [Rapor]. - Brussels, Belgium : Rosa-Luxemburg-Stiftung, 2013.

Kirişçi Kemal TTIP'S ENLARGEMENT AND THE CASE OF TURKEY [Rapor]. - Washington, DC : Woodrow Wilson International Center for Scholars, 2015.

Koç Yurtkur Asuman ve Tay Bayramoğlu Arzu Export Dynamics in Emerging Market Economies [Dergi] // Yönetim ve Ekonomi Cilt:19 Say1:1. - 2012. - s. 19-33.

Köten Abdullah Küresel ve Bölgesel Ticari Gelişmeler: TTIP ve Türkiye [Rapor]. - Yayın No:64 : Ankara Sanayi Odası Yayını, 2015.

Krugman P. Scale economies, product differentiation and the pattern of trade [Dergi]. - [basim yeri bilinmiyor] : American Economic Review 70: 950-9, 1980.

Krugman Paul R. ve Obstfeld Maurice International Economics: Theory \& Policy [Kitap]. Boston : The Addison-Wesley, 2009. - Cilt 8. Edition.

Lejour Arjan [ve diğerleri] Economic Incentives for Indirect TTIP Spillovers [Dergi]. - Brussels : Centre for European Policy Studies, 2014. - TTIP Series No. 2 : Cilt No. 94.

Martin Will ve Pham Cong S. Estimating the Gravity Model When Zero Trade Flows Are Frequent and Economically Determined [Dergi]. - [basim yeri bilinmiyor] : World Bank Group, Policy Research Working Paper 7308, 2015.

Martínez-Zarzoso Inmaculada, D. Felicitas Nowak-Lehmann ve Horsewood Nicholas Are regional trading agreements beneficial? Static and dynamic panel gravity models [Dergi]. - [basim yeri bilinmiyor] : North American Journal of Economics and Finance 20, 46-65, 2009.

McKitrick R.Ross The Econometric Critique of Computable General Equilibrium Modeling: The Role of Parameter Estimation [Dergi] // Economic Modeling 15. - 1998. - s. 543-573.

OECD The Benefits of Liberalising Product Markets and Reducing Barriers to International Trade and Investment in the OECD [Rapor]: Working Papers, No. 463/ OECD Economics Department. - [basım yeri bilinmiyor] : OECD Publishing, 2005.

Özcan Burcu ve Özçelebi Oğuzhan İhracata Dayalı Büyüme Hipotezi Türkiye İçin Geçerli Mi? [Dergi] // Yönetim ve Ekonomi Cilt:20 Sayı:1. - 2013. - s. 1-14.

Özçelik Seda Ekmen Turkey's Competition with the EU in the US Market in the Context of TTIP [Dergi]. - [basım yeri bilinmiyor] : International Journal of Trade, Economics and Finance, Vol. 7, No. 5, 2016. - 198-201.

Pavlova Pavlina Beyond economics: the geopolitical importance of the Transatlantic Trade and Investment Partnership [Dergi] // European View 14. - 2015. - s. 209-216.

Pelkmans Jacques [ve diğerleri] EU-US Transatlantic Trade and Investment Partnership: Detailed Appraisal by the EP Ex-ante Impact Assessment Unit of the European Commission's Impact Assessment [Rapor]. - Brussels : EPRS, 2014.

Pelkmans Jacques TTIP: Political and Economic Rationale and Implications [Rapor]. - [basim yeri bilinmiyor] : Intereconomics Forum, 2015. 
Piermartini Roberta ve Teh Robert Demystifying Modelling Methods For Trade Policy [Dergi]. Geneva, Switzerland : World Trade Organization, 2005. - s.52 : Cilt Discussion Paper No 10.

Plummer Michael G., Cheong David ve Hamanaka Shintaro Methodology for Impact Assessment of Free Trade Agreements [Kitap]. - Philippines : Asian Development Bank, 2010.

Ponce Jaime Garcia-Legaz ve Quinlan Joseph TAFTA: The Case for an Open Transatlantic Free Trade Area [Kitap]. - Spain : FAES Foundation for Social Studies and Analysis, 2013.

Powers William M. Endogenous Liberalization and Sectoral Trade [Rapor]. - Washington, DC : U.S. International Trade Commission Office of Economics Working Paper, 2007.

Raza Werner [ve diğerleri] ASSESS_TTIP: Assessing the Claimed Benefits of the Transatlantic Trade and Investment Partnership (TTIP) [Rapor]. - Vienna, Austria : Austrian Foundation for Development Research, OFSE, 2014.

Rojas-Romagosa Hugo Potential economic effects of TTIP for the Netherlands and the EU [Dergi] // CPB Netherlands Bureau for Economic Policy Analysis. - 2016.

Rose A. ve van Wincoop E. National money as a barrier to international trade: the real case for currency union [Dergi]. - [basim yeri bilinmiyor] : American Economic Review 91(2): 38690, 2001.

Santos Silva J. ve Tenreyro S. The log of gravity [Dergi]. - [basım yeri bilinmiyor] : The Review of Economics and Statistics 88: 641-58, 2006.

Schneider Michael Mobilising the masses: a grass-roots communication strategy for TTIP [Dergi] // European View 14. - 2015. - s. 201-207.

SER Key points of SER's advisory report on TTIP [Rapor]. - The Netherlands: Social and Economic Council of the Netherlands, 2016.

Şahin İlker Demir Çelik Sektörü [Rapor]. - İstanbul : Türkiye İş Bankası İktisadi Araştırmalar Bölümü, 2015.

The World Bank Evaluation of the EU-Turkey Customs Union [Rapor]. - 2014.

Timbergen Jan Shaping the World Economy: Suggestions for an International Economic Policy [Dergi]. - New York : Twentieth Century Fund, 1962.

Trapani Lorenzo ve Urga Giovanni Optimal forecasting with heterogeneous panels: A Monte Carlo study [Dergi]. - [basım yeri bilinmiyor] : International Journal of Forecasting 25, 2009. 567-586.

TÜRKONFED Transatlantik Ticaret ve Yatırım Ortaklığı'nın (TTIP) Türkiye'deki KOBİ'lere Etkisi ve Politika Önerileri [Rapor]. - [basım yeri bilinmiyor] : Türk Girişim ve İş Dünyası Konfederasyonu, 2016.

Urata Shujiro ve Okabe Misa The Impacts of Free Trade Agreements on Trade Flows: An Application of the Gravity Model Approach [Dergi]. - [basim yeri bilinmiyor] : RIETI Discussion Paper Series 07-E-052, 2007.

Ülengin Füsun [ve diğerleri] Effects of quotas on Turkish foreign trade: A gravity model [Dergi]. [basım yeri bilinmiyor] : Transport Policy 38, 1-7, 2015.

Vandenbussche H., Wooton I. ve Venables A. Enhancing economic cooperation between the EU and the Americas: an economic assessment [Rapor]. - University of Strathclyde Glasgow: CEPR, 2002.

Villaverde Jose ve Maza Adolfo The Effects of the TTIP on EU Countries: An Ex-Ante Evaluation [Dergi]. - [basım yeri bilinmiyor] : Revista De Economia Mundial 42, 2016. - 169-192.

Westerlund Joakim ve Wilhelmsson Fredrik Estimating the gravity model without gravity using panel data [Dergi]. - Lund, Sweden : Department of Economics, Lund University, 2006.

WTO A Practical Guide to Trade Policy Analysis [Rapor]. - Geneva, Switzerland : United Nations and World Trade Organization, 2012.

Xiong Bo ve Chen Sixia Estimating Gravity Equation Models in the Presence of Sample Selection and Heteroskedasticity [Konferans]. - Seattle, Washington: Agricultural \& Applied Economics Association's 2012 AAEA Annual Meeting, 2012.

Zsohar Peter Short Introduction to the Generalized Method of Moments [Dergi] // Hungarian Statistical

Review,

Special

Number 
(http://www.ksh.hu/statszemle_archive/2012/2012_K16/2012_K16_150.pdf) . - 2012. - s. 170.

\section{SUMMARY}

In recent years, Transatlantic Trade and Investment Partnership (TTIP) project which has being discussed between European Union (EU) and United States of America (USA) is a quite important agenda topic that has being tried to evaluate effects on both global scale and in its entirety intensively. The prestudies regarding to the evaluation of macroeconomic effects of the project, generally are in positive expectations for the EU and USA economies. The expectation about global economy is also tough as would be positive (Ponce \& Quinlan, 2013, s. 277-278). In the analyses those are done by varied research institutions, mainly general equilibrium analysis is used. At the studies, impacts of the economic integration is measured with consideration of trade changes under the aspect of free trade agreement of the project that means just removing the current trade barriers (tariffs and non-tariff barriers) among the partners. However, the aims of the project those apart from free trade agreement (FTA) and their impacts also have being discussed intensively (Hilary, 2013). The two of the most important economists in today's world, Nobel laureate Paul Krugman (January 2015) and Joseph Stiglitz (May 2015), had expressed their concerns and negative thoughts about the issue. Even though expectations over possibilities of the TTIP project whether come into action were gaining importance during time when researches in this study applied, particularly after the presidential election at the USA, it could be emphasized that the possibilities over the project whether put into practice had been weakened due to political stance of Donald Trump in this regard. Nevertheless, it is anticipated that this study can be support both academic and industrial studies with constructed export model using trade policy variables for iron and steel industry and its empirical analysis findings.

Apart from critics and discussions over the TTIP project, this study focuses only FTA aspect of it that means impacts on exports with changing tariffs as a result of the project. The analyzing studies in the literature are differing from each other in terms of modeling and scenario designs. Eventually, the impact of TTIP on third countries will depend on a range of factors such as the degree of participation in global value chains that involve TTIP countries, the nature of preexisting preferential arrangements between TTIP economies and third countries, the economic structure of economies and what this means for the nature of involvement with parties to TTIP, and the ability of outsiders to align themselves with TTIP's regulatory arrangements (Akman, Evenett, \& Low, 2015, s. 2).

The reason to choose iron-steel industry is about its importance into the Turkish economy and importance of its linkage with other industries (The direct share of the iron-steel industry in the Turkish national income is about \%1.2). The model used in the study is Gravity Model which is an econometric approach explains the international trade with the size of the economies those subject the trade and variables those represents the cost of trade. The model which is also 
used to evaluate the impacts of the trade policies could be stated as a broad and well-accepted method in the literature. The iron-steel exports that modeled with gravity method and its sensitivity with tariffs and FTAs are computed as a result of analyses. The generated random values with limits of statistical range of parameters regarding the sensitivities under the Monte-Carlo simulation approach are evaluated together with generated tariff changes those are also specified range of limits. The meaning of TTIP project in terms of tariffs for iron-steel exports of Turkey is about removing the current tariff levels this is over \%0.09 applied by the USA recent years (The current rates are zero for the EU). Additionally, it could also expect that creating a FTA would generate acceleration for the bilateral trade flows. According to the simulation results, the calculated change in the iron steel exports is between 18 to 24 percent under the both affects. The tariff sensitivity of the iron steel exports is calculated as \%10.08 for response to change of tariffs as $1 \%$. Based on author calculations under partial equilibrium approach, this sensitivity is calculated as -1.19 under logarithmic scale. Therefore, with removing the factors (such as tariffs or non-tariff barriers those cause additional costs) through an FTA, increase on exports could be expected. But, import tariff rates of the EU and USA applying to Turkey is close the zero on average. The evaluation of the impacts of the project only with this perspective offers very limited point of view about the exporting. Hence, , national income changes in global scale as a result of the project and tariff rates those applied by the other countries also should been considered to evaluate the effects of the project properly. 